\title{
Preparations, Characterizations, and a Comparative Study on Photovoltaic Performance of Two Different Types of Graphene/TiO 2 Nanocomposites Photoelectrodes
}

\author{
Uea-aree Kanta, ${ }^{1}$ Voranuch Thongpool, ${ }^{2}$ Weradesh Sangkhun, ${ }^{1}$ \\ Nutthapon Wongyao, ${ }^{3}$ and Jatuphorn Wootthikanokkhan ${ }^{1}$ \\ ${ }^{1}$ Nanotec-KMUTT Center of Excellence on Hybrid Nanomaterials for Alternative Energy (HyNAE), School of Energy, \\ Environment and Materials, King Mongkut's University of Technology Thonburi, Bangkok 10140, Thailand \\ ${ }^{2}$ Division of Physics, Faculty of Science and Technology, Rajamangala University of Technology Thanyaburi, Klong 6, \\ Thanyaburi, Pathum Thani 12110, Thailand \\ ${ }^{3}$ Fuel Cells and Hydrogen Research and Engineering Center, King Mongkut's University of Technology Thonburi, \\ Bangkok 10140, Thailand \\ Correspondence should be addressed to Jatuphorn Wootthikanokkhan; jatuphorn.woo@kmutt.ac.th
}

Received 5 September 2016; Revised 15 December 2016; Accepted 10 January 2017; Published 21 March 2017

Academic Editor: Xuping Sun

Copyright (C) 2017 Uea-aree Kanta et al. This is an open access article distributed under the Creative Commons Attribution License, which permits unrestricted use, distribution, and reproduction in any medium, provided the original work is properly cited.

\begin{abstract}
This research work undertook a comparative study of the promoting effects of graphene in $\mathrm{TiO}_{2}$ photoanodes. The aim of this work was to investigate the effects of the types and concentration of reduced graphene oxides (rGO) on structure properties and the photovoltaic performance of $\mathrm{TiO}_{2}$ based electrodes. Graphene oxide (GO) was prepared by using modified Hammer's method. Next, GO was reduced by using two different approaches, which were the chemical reduction with vitamin $\mathrm{C}$ and thermal reduction. The latter approach was also carried out in situ during the fabrication and heat treatment processes of the dye-sensitized solar cells (DSSCs). From the results, it was found that the photovoltaic performance of the DSSCs containing the $\mathrm{GO} / \mathrm{TiO}_{2}$ electrode, in which the GO phase experienced an in situ thermal reduction, was superior to those containing $\mathrm{rGO} / \mathrm{TiO}_{2}$. It was also found that the power conversion efficiency of the DSSCs changed with the concentration of graphene in a nonlinear fashion. The optimum concentrations of graphene, corresponding to the highest $\mathrm{PCE}$ values of the $\mathrm{GO} / \mathrm{TiO}_{2}$ based $\mathrm{DSSC}(3.69 \%)$ and that of the $\mathrm{rGO} / \mathrm{TiO}_{2}$ based cell (2.90\%), were $0.01 \mathrm{wt} \%$ and $0.03 \mathrm{wt} \%$, respectively.
\end{abstract}

\section{Introduction}

The development of materials for the new generation of solar cells has been an interesting subject that has gained more and more interest over the past decade. This is attributed to several advantages of immerging photovoltaic devices, including the relatively low cost and simple fabrication process and the possibility of enlarging the production scale by using existing industrial technologies, such as printing. Besides, the photovoltaic performance of this new generation of solar cells is also interesting. At the present time, the power conversion efficiency values of the best research organic photovoltaic cell (OPV), dye-sensitized solar cell (DSSC), and the perovskite solar cell (PSC), certified by the NREL, are $11.5 \%, 11.9 \%$, and $22.1 \%$, respectively [1]. However, further developments have yet to be carried out before these devices can be massproduced and used commercially. These include three main research issues which are (1) the improvement of stability and lifetime of the solar cell, (2) the development of alternative materials which are less toxic and of lower cost, and (3) the enhancement of their cell efficiency, taking into account the fact that the enlargement of the cell size and its active area is usually achieved at the expense of cell efficiency. To achieve the above goals, several approaches have been used, including the development of better materials and the designs of new solar cell configuration and architecture.

Nanocrystalline titanium dioxide film $\left(\mathrm{TiO}_{2}\right)$ coated on a transparent conductive oxide glass has been widely used 
as a photoanode in many types of the new generation solar cells, including DSSC and PSC. In this context, the transportation of the photogenerated electrons across the $\mathrm{TiO}_{2}$ nanoparticles network is considered to be one important factor determining the performance of the solar cell. Without efficient charge transport, electron-hole recombination can occur, and that can lead to a relatively low efficiency of the cells. To enhance the electron transport of a DSSC photoelectrode, $\mathrm{TiO}_{2}$ might be treated with some chemicals such as nitrogen, $\mathrm{Sn}, \mathrm{Cu}, \mathrm{Zr}, \mathrm{CNT}$, and graphene. For example, Ding et al. [2] prepared reduced graphene oxide ( $\mathrm{rGO}$ ) by treating graphene oxide (GO) with a reducing agent prior to mixing with $\mathrm{TiO}_{2}$ of various weight compositions (0.25-1.25 wt\% of $\mathrm{rGO}$ ). The $\mathrm{rGO} / \mathrm{TiO}_{2}$ composite was then applied as a photoanode for the DSSC and the photovoltaic performance was studied. It was found that the power conversion efficiency of the DSSC changed with the concentration of rGO in a nonlinear fashion. Specifically, the PCE values initially increased with the concentration of rGO to the maximum and then decreased again with a further increase of rGO. The greatest PCE value (7.89\%) was obtained when $0.75 \mathrm{wt} \%$ of rGO was added to the $\mathrm{TiO}_{2}$. Alternatively, Tang et al. [3] incorporated rGO into $\mathrm{TiO}_{2}$ via molecular grafting. In that experiment, by properly controlling the oxidation time during the chemical exfoliation process, the hydroxyl groups on the surface of the graphene sheet were optimized, and a strong interaction between $\mathrm{rGO}$ and $\mathrm{TiO}_{2}$ was induced, through the chemisorption. As a result, the PCE values of the DSSCs increased by more than five times compared to that of the cell containing the bare $\mathrm{TiO}_{2}$ electrode. Recently, a $\mathrm{rGO} / \mathrm{TiO}_{2}$ electrode was also applied to a perovskite solar cell (PSC). For example, work by Han et al. [4] demonstrated that the solar cell based on $\mathrm{rGO} / \mathrm{TiO}_{2}$ nanocomposite electrode had higher $J_{\mathrm{sc}}$, fill factor, and $V_{\mathrm{oc}}$ values than those of the devices based on the bare $\mathrm{TiO}_{2}$ electrode. By properly controlling the film thickness and dispersion of rGO, the maximum PCE value of the PSC (14.5\%) was obtained when $0.4 \mathrm{vol} \%$ of $\mathrm{rGO}$ was added to the $\mathrm{TiO}_{2}$. This accounted for approximately an $18 \%$ increase, as compared to that of the normal PSC based on a bare $\mathrm{TiO}_{2}$ electrode (11.5\%).

Practically, graphene, in a form of colloidal suspension, can be prepared via exfoliation of graphene oxide (GO) followed by a chemical reduction. Reducing agents that can be used for the chemical reduction of GO include hydrazine, dimethyl hydrazine, hydroquinone, and $\mathrm{NaBH}_{4}$ [5]. Particularly, hydrazine is widely used for reduction of GO because of its high efficiency as compared to that of other chemicals. However, the obtained graphene is unstable in water. It can be aggregated owing to the strong van der Waals force between molecules. To further enhance stability and dispersion of graphene in aqueous media, Swain and Bahadur [6] added two cross-linking polymers, polyvinylpyrrolidone (PVP) and poly(vinyl alcohol) (PVA), to the hydrazine based reduction process. However, most of the abovementioned reducing agents are known to be toxic and some of them can be explosive. In this regard, attempts have been made to explore the use of some alternative reducing agents to prepare graphene. For example, Fernández-Merino et al. [7] and Zhang et al. [8] reported the use of L-ascorbic acid (vitamin C) as a reducing agent for preparing GO at room temperature. The results claimed that the average electrical conductivity values of the rGO prepared by vitamin $\mathrm{C}$ are comparable to those obtained by using hydrazine.

Alternatively, GO can be reduced via other processes such as photoreduction $[9,10]$, electrochemical reduction [11], and thermal treatment at temperatures ranging between 100 and $150^{\circ} \mathrm{C}$ [12]. In this study, a reduction of GO via the thermal treatment is of interest because this approach could be suitable with the DSSC application, taking into account the fact that the $\mathrm{TiO}_{2}$ coated FTO usually underwent heat treatment (or annealing) during the fabrication process in order to get rid of some organic residual. In relation to this study, it can be expected that the GO phase in the $\mathrm{GO} / \mathrm{TiO}_{2}$ composites could be in situ reduced during annealing. This means that the GO might be applied to the solar cell system without undertaking a prereduction step. In fact, better photovoltaic performance of the thermally reduced $\mathrm{GO} / \mathrm{TiO}_{2}$ photoelectrode has been demonstrated by several researchers. For example, Wang et al. [13] found that the optimum content of GO was $0.83 \mathrm{wt} \%$. This contributes to the increase in PCE of the DSSC from $1.79 \%$ to $2.78 \%$. Kusumawati et al. [14] reported that the power conversion efficiency of the DSSC increased from $5.78 \%$ to $7.49 \%$ when $1.2 \mathrm{wt} \%$ of GO was added to the $\mathrm{TiO}_{2}$ photoelectrode. Cheng and Stadler [15] modified $\mathrm{TiO}_{2}$ with $\mathrm{GO}$ and found that the power conversion efficiency of DSSC containing $1.6 \mathrm{wt} \%$ of GO in the composite electrode $\left(\mathrm{GO} / \mathrm{TiO}_{2}\right)$ was $7.68 \%$, which is much greater than that which employed the bare $\mathrm{TiO}_{2}$ electrode (4.78\%). Chou et al. [16] reported that when about $1.5 \mathrm{~mL}$ of GO solution was mixed with $\mathrm{TiO}_{2}$, the optimum PCE value $(5.26 \%)$ of the DSSC containing the composite electrode was obtained.

From the above literature, it is evident that graphene is an effective and interesting chemical that can be used to modify $\mathrm{TiO}_{2}$ to enhance the photovoltaic performance of the electrode in dye-sensitized solar cells. However, there has been no report on a comparative study of photovoltaic performance graphene/ $\mathrm{TiO}_{2}$ photoelectrodes, in which the reduced graphene oxide was prepared by using a different approach. It was believed that the optimum concentration of graphene for promoting $\mathrm{TiO}_{2}$ was dependent on the systems and had yet to be optimized. In this study, the graphene $/ \mathrm{TiO}_{2}$ electrodes made from two different approaches were studied. These are (1) the system made by mixing $\mathrm{GO}$ with $\mathrm{TiO}_{2}$ followed by an in situ thermal treatment $\left(\mathrm{GO} / \mathrm{TiO}_{2}\right)$ and $(2)$ the system prepared via prereduction of graphene oxide with vitamin $\mathrm{C}$, followed by mixing it with titanium dioxide $\left(\mathrm{rGO} / \mathrm{TiO}_{2}\right.$. More details concerning the preparation techniques can be found in the experimental part of this paper. The primary aim of this work is to investigate the effects of the type and concentration of graphene on structure properties and the photovoltaic performance of the $\mathrm{TiO}_{2}$ based electrode. Attempts were also made to characterize the various materials and DSSCs, in terms of light absorption, percentage dye loading, and the interfacial electrical properties, in order to elucidate some possible mechanisms behind the promoting effect of graphene. 


\section{Experimental}

2.1. Chemicals. Titanium dioxide (Evonik, P25, 75\% anatase, average particle size of $21 \mathrm{~nm})$, graphite $(<20 \mu \mathrm{m}$, synthetic grade), isopropanol (99.5\%, anhydrous), fluorine-doped tin oxide (FTO) glass (resistivity $\sim 7 \Omega /$ sq, with the thickness of glass and FTO of $2 \mathrm{~mm}$ and $660 \mathrm{~nm}$, resp.), acetonitrile (99.8\%, anhydrous), and $t$-butanol (99.5\%, anhydrous) were purchased from Sigma-Aldrich. Sulfuric acid (95-97\% AR grade), hydrochloric acid (37\%, AR grade), and hydrazine ( $80 \%$ in water, synthesis grade) were obtained from Merck Co. Ltd. Dye (Ruthenizer 535-bisTBA, N719) was purchased from Solalonix and platinum paste was supplied from Solaronix. Potassium permanganate used was of AR grade from Ajax Finechem. Ascorbic acid (AR grade) was supplied by Suksapan Paint Co. Ltd. All of the above chemicals were used as received.

2.2. Synthesis of the Reduced Graphene Oxides. Graphene oxide (GO) was firstly prepared by using the modified Hummer method $[17,18]$. Graphite powder $(2.0 \mathrm{~g})$ was mixed with $1.5 \mathrm{~g}$ of sodium nitrate and $46 \mathrm{~mL}$ of conc. sulfuric acid $\left(\mathrm{H}_{2} \mathrm{SO}_{4}, 98 \%\right.$, aqueous) and stirred in an ice bath. Next, $6 \mathrm{~g}$ of potassium permanganate $\left(\mathrm{KMnO}_{4}\right)$ was gradually added, dropwise, to the content in the reaction flask at $20^{\circ} \mathrm{C}$. The mixture was stirred for a further $3 \mathrm{~h}$. Noteworthy is that the reaction between $\mathrm{KMnO}_{4}$ and the graphite solution is exothermic and thus attempts were made to maintain the temperature below the ambient temperature $\left(35^{\circ} \mathrm{C}\right)$. Next, $100 \mathrm{~mL}$ of deionized water was added to the mixture, followed by adding $10 \mathrm{~mL}$ of hydrogen peroxide (30\% solution). During the addition of $\mathrm{H}_{2} \mathrm{O}_{2}$, change in color of the content in the reaction flask toward yellowish and eventually brown can be observed. This indicates that the residual permanganate and manganese dioxide were reduced [19]. After that, the product was washed with an aqueous solution of hydrochloric acid $(2 \mathrm{M}$ of $10 \% \mathrm{HCl}$ ) and the precipitate was further washed with deionized water until reaching neutral $\mathrm{pH}(\mathrm{pH}=7.0)$. Finally, the product was dried in an oven at $60^{\circ} \mathrm{C}$ until reaching a constant weight.

To reduce GO via a chemical treatment process, $0.3 \mathrm{~g}$ of the synthesized GO was dissolved in $100 \mathrm{~mL}$ of deionized water and then sonicated for $30 \mathrm{~min}$. After that, $100 \mathrm{mg}$ of ascorbic acid (vitamin C) was added to the solution and the mixture was sonicated for a further $2 \mathrm{~h}$. The content in the reaction flask was filtrated and washed with distilled water several times to remove the remaining $\mathrm{VC}$ and residues. Finally, the filtrate was dried in an oven at $60^{\circ} \mathrm{C}$ for $12 \mathrm{~h}$.

2.3. Preparation of Graphene Oxides $/ \mathrm{TiO}_{2}$ Composites $\left(\mathrm{GO} / \mathrm{TiO} \mathrm{O}_{2}\right.$ and $\left.r \mathrm{GO} / \mathrm{TiO}_{2}\right)$. A given amount of the synthesized $\mathrm{GO}$ powder (varying from 0.2 to $0.6,1.0,2.0$, and $3.0 \mathrm{mg}$ ) was dissolved in $100 \mathrm{~mL}$ of deionized water and sonicated for $30 \mathrm{~min}$. Next, $2 \mathrm{~g}$ of a commercial nanocrystalline $\mathrm{TiO}_{2}$ powder (P25, Degussa) was added to the GO dispersion and then sonicated for a further $1 \mathrm{~h}$. The content in the reaction flask was filtrated and then washed with deionized water several times. Finally, the filtrate was dried in an oven at $60^{\circ} \mathrm{C}$ for $12 \mathrm{~h}$. As a result, $\mathrm{GO} / \mathrm{TiO}_{2}$ nanocomposites with different concentrations of
GO $(0.01,0.03,0.05,0.10$, and $0.15 \mathrm{wt} \%)$ were prepared. In this study, the sample codes for the products were designated as TiO $@ @ G O-01, \mathrm{TiO}_{2} @ G O-03, \mathrm{TiO}_{2} @ G O-05, \mathrm{TiO}_{2} @ \mathrm{GO}-$ 10 , and $\mathrm{TiO}_{2} @ \mathrm{GO}-15$, respectively. For the preparation of reduced graphene oxide/ $/ \mathrm{TiO}_{2}$ nanocomposites, the synthesized rGO was used as a replacement of $\mathrm{GO}$ and similar steps were followed. In this case, the sample codes for $\mathrm{TiO}_{2}$ electrodes containing different concentrations of rGO $(0.01,0.03,0.05,0.10$, and $0.15 \mathrm{wt} \%)$ were designated as TiO $@ @ r G O-01,7 i O_{2} @ r G O-03, T_{2} @ r G O-05,7 i O_{2} @ r G O-$ 10 , and $\mathrm{TiO}_{2} @ \mathrm{rGO}-15$, respectively.

2.4. Preparation of the Electrodes. To prepare the $\mathrm{TiO}_{2}$ based photoanode, fluorine-doped tin oxide (FTO) glass was cut into $25 \times 25\left(\mathrm{~mm}^{2}\right)$ square pieces. The FTO glass substrates were then treated with a hydrochloric acid solution $(\mathrm{HCl}$, $0.2 \mathrm{M}$ ) in an ultrasonic bath for $15 \mathrm{~min}$, followed by washing it with deionized water under the sonication process for $10 \mathrm{~min}$, twice. After that, the substrates were cleaned with isopropyl alcohol and then dried by purging with nitrogen gas. In this study, to minimize some electron-hole recombinations at the interfacial zone between electrolyte and FTO layer, an electron transport layer (ETL) made from a thin film of $\mathrm{TiO}_{x}$ was applied into the cell configuration. The $\mathrm{TiO}_{x}$ solgel was firstly prepared by dissolving $0.1 \mathrm{M}$ of titanium(IV) isopropoxide (TTIP) in isopropanol (IPA). Next, the $\mathrm{TiO}_{x}$ film coated onto the FTO glass was prepared by applying $10 \mu \mathrm{L}$ of the $\mathrm{TiO}_{x}$ sol-gel onto the FTO glass substrate via a rapid convection deposition technique, at a deposition rate of $2 \mathrm{~mm} / \mathrm{s}$. The $\mathrm{TiO}_{x}$ coated FTO was then annealed at $500^{\circ} \mathrm{C}$ for $1 \mathrm{~h}$. Next, different types of graphene oxides $/ \mathrm{TiO}_{2}$ nanocomposites were applied onto the ETL coated FTO glass. $10 \mu \mathrm{L}$ of titanium tetraisopropoxide (TTIP) and $0.5 \mathrm{~mL}$ of ethanol were added to $0.20 \mathrm{~g}$ of the synthesized $\mathrm{GO} / \mathrm{TiO}_{2}$ (or $\mathrm{rGO} / \mathrm{TiO}_{2}$ ) powders, using a sonication process. The composite paste $\left(\mathrm{GO} / \mathrm{TiO}_{2}\right.$ paste and/or $\mathrm{rGO} / \mathrm{TiO}$, paste) was then applied onto the ETL coated FTO glass by using a doctor blade technique. Specifically, a microscope slide $\left(90^{\circ}\right.$ ground edges, Marienfeld Superior, from Paul Marienfeld GmbH \& Co. KG, Germany) was used as a blade. The $\mathrm{rGO} / \mathrm{TiO}_{2}$ paste was placed and spread on the FTO substrate by manually moving the blade forward at the angle of $45^{\circ}$ with respect to the FTO substrate. This process was repeated 8 times until a uniform thin sheet of the material was formed. Then, the prepared electrode was annealed at $450^{\circ} \mathrm{C}$ for $30 \mathrm{~min}$, in order to get rid of some residual organic compounds originated from the graphene/ $/ \mathrm{TiO}_{2}$ paste and $\mathrm{TiO}_{x}$ precursor. At this stage, it is worth mentioning in the case of $\mathrm{GO} / \mathrm{TiO}_{2}$ electrode that it was expected that the GO phase in the composite layer would also be thermally reduced to graphene, leading to the formation of graphene/ $\mathrm{TiO}_{2}$ based photoelectrode. Finally, platinum coated FTO, used as a counter electrode, was prepared by coating Pt paste onto the FTO glass substrate via a doctor blade technique. The Pt coated FTO glass was then annealed at $500^{\circ} \mathrm{C}$ for $1 \mathrm{~h}$.

2.5. Fabrication of the Dye-Sensitized Solar Cells (DSSCs). To commence the fabrication process of the DSSCs, the prepared photoanode had to be sensitized firstly by immersing it in 
a staining jar, containing a solution of the dye (N719 in a cosolvent, $5 \mathrm{~mL}$ of anhydrous acetonitrile, and $5 \mathrm{~mL}$ of tertbutanol) at $80^{\circ} \mathrm{C}$ for $15 \mathrm{~min}$. The staining jar was then kept in the dark for a further $18 \mathrm{~h}$. After that, the dye absorbed photoanode was rinsed with anhydrous acetonitrile, followed by purging with nitrogen gas, and then dried in an oven at $80^{\circ} \mathrm{C}$ for $15 \mathrm{~min}$. In this regard, the amount of dye loading in the photoelectrode was determined by using UV spectrophotometry, in combination with the Bear and Lambert equation, after complete dye desorption in a $0.1 \mathrm{~mol} \cdot \mathrm{L}^{-1}$ $\mathrm{NaOH}$ solution.

The prepared dye-sensitized photoanode was than assembled with Pt coated FTO counter electrode into a sandwich type cell, using a precut $\left(4 \times 3 \mathrm{~cm}^{2}\right.$ rectangular) sealing film (ethylene-acrylic acid copolymer, Surlyn from DuPont) as a frame. The cell was then sealed by applying a heat gun. Next, the electrolyte solution (HI-30 from Solaronix) was injected into the cells through a hole drilled in the counter electrode. Finally, the holes were plugged with the Kapton tape in order to avoid some leakage and evaporation of the liquid inside the cells.

2.6. Testing on Power Conversion Efficiency of the DSSCs. Current density-voltage $(J-V)$ characteristics of the various cells were measured by using the Keithley 2400 source meter under 1.5 AM. The light source was generated by a solar simulator (Newport $91150 \mathrm{~V}$ model, $1000 \mathrm{~W}$, xenon lamp), equipped with a $1.5 \mathrm{G}$ air mass filter. The active area of the DSSC was $0.4 \times 1.0 \mathrm{~cm}^{2}$.

2.7. Characterizations. Functional groups in the chemical structures of synthesized graphene were monitored by using a Fourier transform infrared spectrometer (Thermo Nicolet 6700) in a transparent mode. The sample was prepared by using a $\mathrm{KBr}$ technique and the spectra were scanned over the wavenumber ranging between 500 and $4000 \mathrm{~cm}^{-1}$. Reduction of GO was also followed up by a Raman technique, using the Raman spectrometer (NTEGRA Spectra, NTMDT) equipped with a $532 \mathrm{~nm}$ laser.

Morphologies of graphene and graphene $/ \mathrm{TiO}_{2}$ composites were examined by using a scanning electron microscope (Nova NanoSEM 450, FEITM) equipped with secondary electron and EXD detectors. Crystal structures of the various materials including $\mathrm{TiO}_{2}$, graphene based materials (GO, rGO), and the $\mathrm{TiO}_{2}$ /graphene composites were determined by using an X-ray diffraction (XRD) technique, using an Xray diffractometer (PANalytical, X'Pert PRO) with $\mathrm{Cu} \mathrm{K} \alpha$ radiation $(\lambda=0.15406 \mathrm{~nm})$. The diffractometer was operated at $30 \mathrm{kV}$ and $40 \mathrm{~mA}$ and the sample was scanned over a $2 \theta$ range of $0-80^{\circ}$. In addition, average crystal sizes of the $\mathrm{TiO}_{2}$ phase in various composites were determined from XRD line-broadening of the $\mathrm{TiO}_{2}$ (101) diffraction peals, using the Scherrer equation as follows:

$$
D=\frac{K \lambda}{\Delta(2 \theta) \cos \theta},
$$

where $\Delta(2 \theta)$ is line-broadening at half the maximum intensity of the (101) peak of anatase, $K$ is the coefficient (0.89), $\theta$ is the diffraction angle, and $\lambda$ is the $\mathrm{X}$-ray wavelength of $\mathrm{Cu}$ $\mathrm{K} \alpha$ radiation $(0.15405 \mathrm{~nm})$.
The reflectance spectra of $\mathrm{TiO}_{2}$ and various graphene/ $\mathrm{TiO}_{2}$ composites, over the wavelength range between 200 and $800 \mathrm{~nm}$, were measured using a UV-Vis-NIR spectrophotometer (Cary 5000, Agilent Technologies). From the reflectance value, the bandgap energy values of $\mathrm{TiO}_{2}$ and graphene/ $/ \mathrm{TiO}_{2}$ composites were determined by using Kubelka-Munk's equation (2) and Planck's equation (3):

$$
F(R)=\frac{(1-R)^{2}}{2 R},
$$

where $F(R)$ is the Kubelka-Munk fraction and $R$ is reflectance.

$$
E_{g}=\frac{h C}{\lambda}
$$

where $E_{g}$ is the bandgap energy $(\mathrm{eV}), h$ is Planck's constant $(\mathrm{J} / \mathrm{s}), C$ is the speed of light $(\mathrm{m} / \mathrm{s})$, and $\lambda$ is the cut-off wavelength $(\mathrm{nm})$.

Electrochemical impedance analysis (EIS) of the various DSSCs was carried out in the dark at $0.75 \mathrm{~V}$ applied bias, using an impedance analyzer (Autolab-PGSTAT 302N). The impedance curves were recorded as Nyquist plots at 10 points per decade by superimposing $10 \mathrm{mV}$ of AC signal onto the cell under potentiostatic mode with the frequency sweep from $1 \mathrm{MHz}$ to $0.5 \mathrm{~Hz}$.

\section{Results and Discussion}

3.1. Characterizations of the Synthesized Graphene. Figure 1 shows the FTIR spectra of graphite, graphene oxide, and the reduced graphene oxides. The absorption peak at $1635 \mathrm{~cm}^{-1}$ in the spectrum of the neat graphite, representing the carboncarbon double bonds $(\mathrm{C}=\mathrm{C})$, can be observed. After treating the graphite via the modified Hummer method, new peaks of 1050 and $1720 \mathrm{~cm}^{-1}$ emerged. These peaks can be ascribed to the presence of $\mathrm{C}-\mathrm{O}$ and $\mathrm{C}=\mathrm{O}$ bonds, respectively. The above change was accompanied by a stronger intensity of the absorption band at $3400 \mathrm{~cm}^{-1}$, which represents the hydroxyl groups. These spectral changes indicate the presence of carbonyl, ether, and hydroxyl groups in the chemical structure of the treated graphite, implying that graphene oxide has been produced. After treating the graphene oxide with vitamin $\mathrm{C}$, the intensity of $\mathrm{OH}$ band $\left(3400 \mathrm{~cm}^{-1}\right)$ and $\mathrm{C}=\mathrm{O}\left(1720 \mathrm{~cm}^{-1}\right)$ and $\mathrm{C}-\mathrm{O}\left(1050 \mathrm{~cm}^{-1}\right)$ peaks decreased. The above spectral changes suggest that the graphene oxide was reduced.

The reduction of graphene oxide by vitamin $\mathrm{C}$ was also confirmed by considering the Raman spectra of graphene oxide (GO) both before and after treating it with vitamin $C$ (Figure 2). Here, the characteristic D band and $G$ band, representing $\mathrm{sp}^{3}$ hybridization and $\mathrm{sp}^{2}$ hybridization of the graphene oxides (both before and after reduction), can be observed at $1344-1364 \mathrm{~cm}^{-1}$ and $1573-1603 \mathrm{~cm}^{-1}$, respectively. Consideration of the $\mathrm{D} / \mathrm{G}$ band intensity ratios (designated as $I_{\mathrm{D}} / I_{\mathrm{G}}$ in Table 1 ) reveals that the $I_{\mathrm{D}} / I_{\mathrm{G}}$ value increased after the reduction of GO. A similar effect was observed by Chen and Yan [12]. This change can be attributed to the decrease in the average size of the in-plane $\mathrm{sp}^{2}$ domains, through the reduction process of GO. After heat treatment, 
TABLE 1: Intensity ratios of the Raman bands $\left(I_{\mathrm{D}} / I_{\mathrm{G}}\right)$ and percentage mass of elements from EDX techniques of graphite, graphene oxide (GO), and reduced graphene oxide (rGO).

\begin{tabular}{|c|c|c|c|c|c|c|}
\hline \multirow{3}{*}{ Samples } & \multicolumn{3}{|c|}{ Before heat treatment } & \multicolumn{3}{|c|}{ After heat treatment } \\
\hline & \multirow{2}{*}{$\begin{array}{c}\text { Raman bands } \\
I_{\mathrm{D}} / I_{\mathrm{G}}\end{array}$} & \multicolumn{2}{|c|}{ Percentage mass from EDX } & \multirow{2}{*}{$\begin{array}{c}\text { Raman bands } \\
I_{\mathrm{D}} / I_{\mathrm{G}}\end{array}$} & \multicolumn{2}{|c|}{ Percentage mass from EDX } \\
\hline & & $\mathrm{C}$ & $\mathrm{O}$ & & C & $\mathrm{O}$ \\
\hline Graphite & 0.257 & N/A & N/A & $\mathrm{N} / \mathrm{A}$ & N/A & N/A \\
\hline $\mathrm{GO}$ & 0.802 & 52.55 & 47.44 & 0.960 & 52.58 & 47.40 \\
\hline $\mathrm{rGO}$ & 0.975 & 71.04 & 28.95 & 1.002 & $64.11,15.98$ & $35.89,84.02$ \\
\hline
\end{tabular}

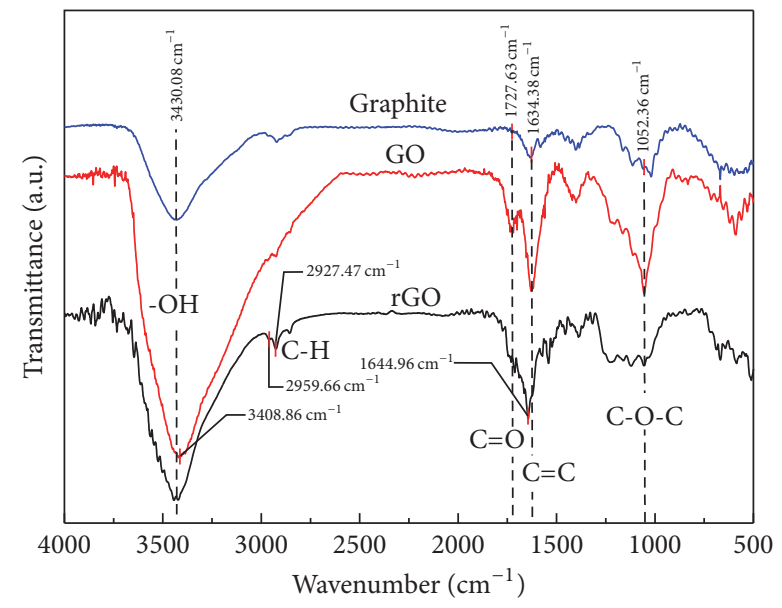

FIGURE 1: FTIR spectra of graphite, graphene oxide (GO), and reduced graphene oxide (rGO).

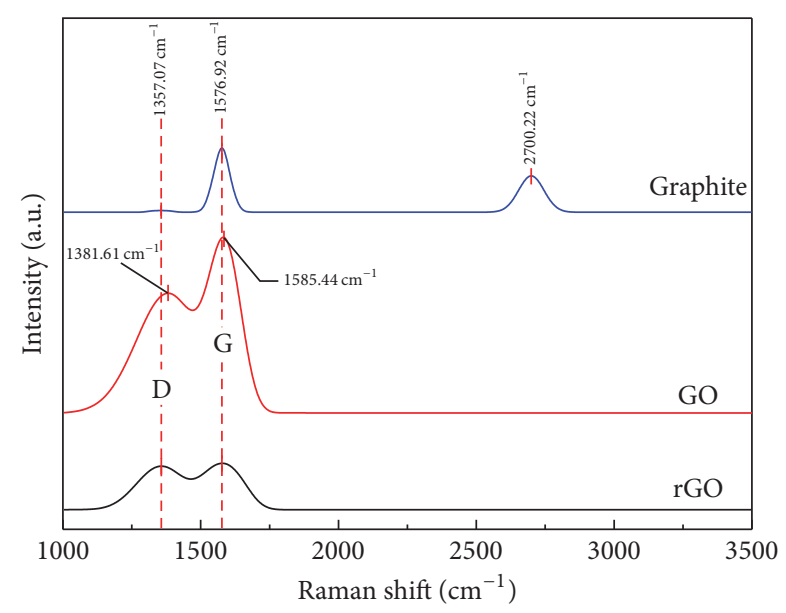

FIGURE 2: Raman spectra of graphite, graphene oxide, and reduced graphene oxide.

the Raman spectra of both GO and rGO still exist. The $I_{\mathrm{D}} / I_{\mathrm{G}}$ value of $\mathrm{GO}$ increased after the heat treatment. It was apparent that the hybridization of GO had been transformed during the heat treatment process. The above effect was not the case for heat treated rGO.

The formation of reduced graphene oxide, via either chemical reaction with vitamin $\mathrm{C}$ or thermal reduction, can also be followed up by considering the XRD patterns of various graphene based materials (Figure 3). After experiencing the chemical reduction, the characteristic peaks at $2 \theta=10.1^{\circ}$,

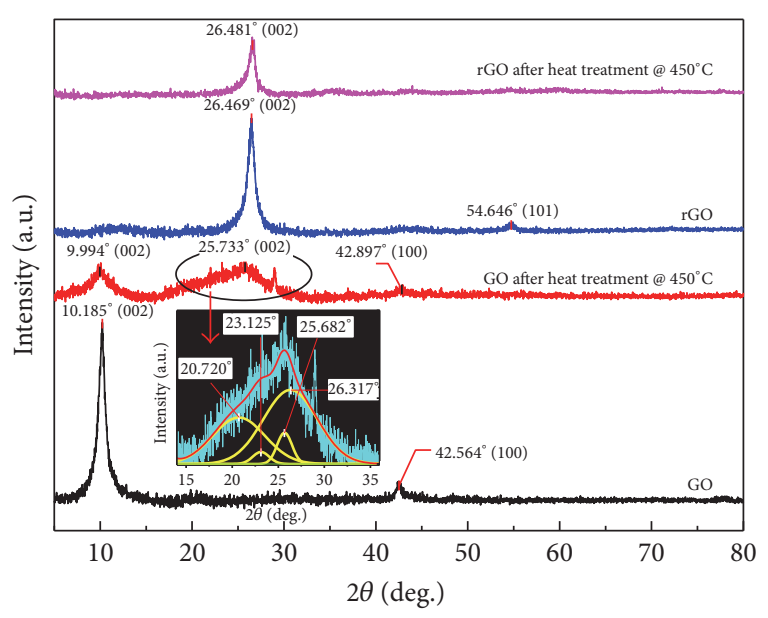

FIGURE 3: XRD patterns of GO and rGO, both before and after heat treatment.

representing graphene oxide, shifted to $2 \theta=26.33^{\circ}$ and $53.45^{\circ}$. The positions of these peaks correspond to those of the neat graphite. Similarly, after the heat treatment process, the XRD pattern of graphene oxide significantly changed. The intensity of the peak at $2 \theta=10.1^{\circ}$ decreased whereas a new peak at $26.31^{\circ}$ emerged. Again, the positions of these peaks are close to those of the neat graphite and the reduced graphene oxide, respectively. These indicate that the graphene oxide was partly reduced through the heat treatment process.

Figure 4 shows the SEM images of graphene oxide and reduced graphene oxide. The presence of two-dimensional wrinkled sheets measuring the length of several micrometers can be noted from the SEM images of both GO and rGO. After the heat treatment, the characteristic wrinkled sheets of GO were still retained. This was also the case for $\mathrm{rGO}$ that experienced the same heat treatment process. Attempts were also made to characterize GO and $\mathrm{rGO}$ specimens by using an EDX technique. From the quantitative analysis, the amounts of oxygen $(\mathrm{O})$ and carbon $(\mathrm{C})$ elements were determined and are summarized in Table 1 . The percentage mass of the oxygen atom significantly decreased from $47.44 \%$ to $28.95 \%$ after treating the GO with the reducing agent (vitamin $\mathrm{C}$ ). This can be considered as indirect evidence supporting the formation of rGO. Based on the above results from FTIR, Raman spectra, XRD, SEM, and EDX, it can be concluded that the GO and rGO were successfully prepared.

3.2. Effects of $G O$ and $r G O$ on Structures and Properties of $\mathrm{TiO}_{2}$. Figure 5 shows the overlaid XRD patterns of $\mathrm{TiO}_{2}$ 
TABLE 2: Crystal size and bandgap energy values of $\mathrm{TiO}_{2}$ and graphene/ $\mathrm{TiO}_{2}$ composites.

\begin{tabular}{|c|c|c|c|c|}
\hline \multirow{2}{*}{ Sample codes } & \multicolumn{2}{|c|}{ Type \& content of graphene } & \multirow{2}{*}{ Crystallite size $(\mathrm{nm})^{\#}$} & \multirow{2}{*}{ Bandgap energy $(\mathrm{eV})$} \\
\hline & GO (wt $\%)$ & rGO (wt\%) & & \\
\hline $\mathrm{TiO}_{2}$ & - & - & 19.27 & 3.03 \\
\hline Ti@GO-01 & 0.01 & - & 19.47 & 2.98 \\
\hline Ti@GO-03 & 0.03 & - & 19.61 & 2.97 \\
\hline Ti@GO-05 & 0.05 & - & 19.81 & 2.98 \\
\hline Ti@GO-10 & 0.10 & - & 19.01 & 2.99 \\
\hline Ti@rGO-01 & - & 0.01 & 18.28 & 2.95 \\
\hline Ti@rGO-03 & - & 0.03 & 19.25 & 2.98 \\
\hline Ti@rGO-05 & - & 0.05 & 19.45 & 3.00 \\
\hline Ti@rGO-10 & - & 0.10 & 19.56 & 3.02 \\
\hline
\end{tabular}

\# The average crystal size estimated from XRD line-broadening of the $\mathrm{TiO}_{2}$ (101) diffraction peaks.

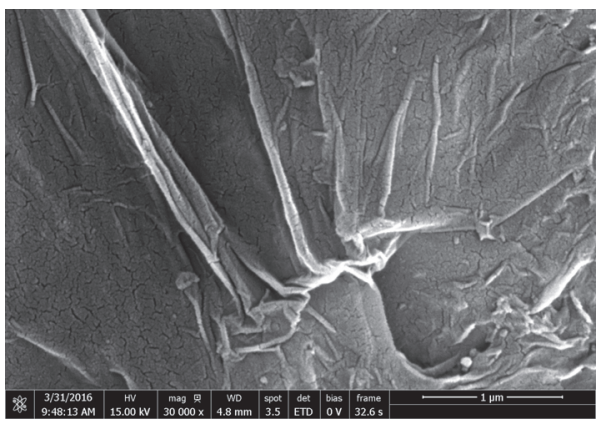

(a)

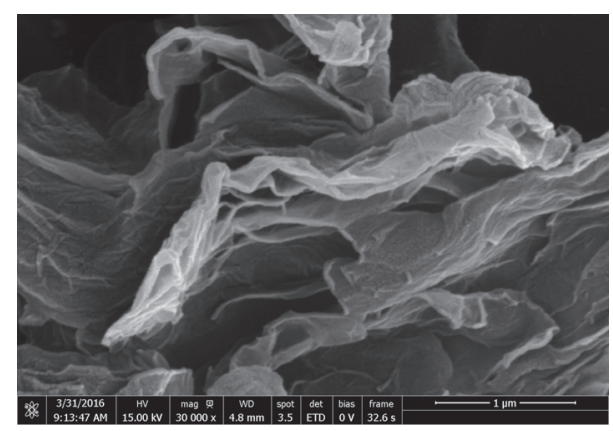

(c)

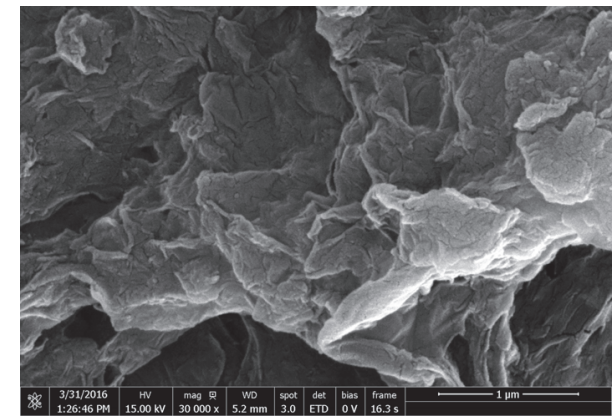

(b)

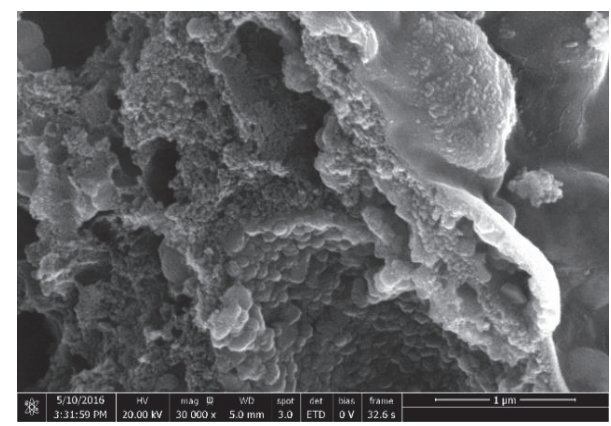

(d)

FIGURE 4: SEM micrographs of GO (a) and rGO (b); the heat treated GO (c); and the heat treated rGO (d).

and various graphene/ $\mathrm{TiO}_{2}$ composites. The diffraction peaks representing anatase and rutile phases $\mathrm{TiO}_{2}$ can be assigned in accordance with JCPDS cards numbers 21-1272 and 211276. After mixing $\mathrm{TiO}_{2}$ with graphene, the characteristic peaks of $\mathrm{TiO}_{2}$ still exist. Attempts were also made to determine the average crystal size of $\mathrm{TiO}_{2}$ by using the Scherrer equation. The results, illustrated in Table 2, show that the crystal size of $\mathrm{TiO}_{2}$ did not change significantly with the presence of either GO or rGO. It seems that the characteristic peaks of GO and rGO were obscured by those of $\mathrm{TiO}_{2}$, which is the majority of the composite materials. In this regard, a change in XRD patterns of graphene/ $\mathrm{TiO}_{2}$ upon heat treatment should not be expected.
Consideration of SEM images of the composites (Figure 6) reveals that the porous structure consisting of interconnected particulate structure of the titania was retained. The above results indicate that the presence of graphene (either GO or rGO) did not affect the morphology and microstructure of the titania. Again, this can be ascribed to the fact that the amount of GO and $\mathrm{rGO}$ used for modifying $\mathrm{TiO}_{2}$ was relatively low compared to that of the neat titania. Figure 7 shows the cross-sectional SEM image of the $\mathrm{TiO}_{2}$ based photoelectrode. The porous structure of the mesoscopic layer, made from $\mathrm{GO} / \mathrm{TiO}_{2}$, can be observed. This layer was perfectly laid on top of the $\mathrm{TiO}_{x}$ coated FTO. The thickness values of each layer were approximately $5 \mu \mathrm{m}$, 


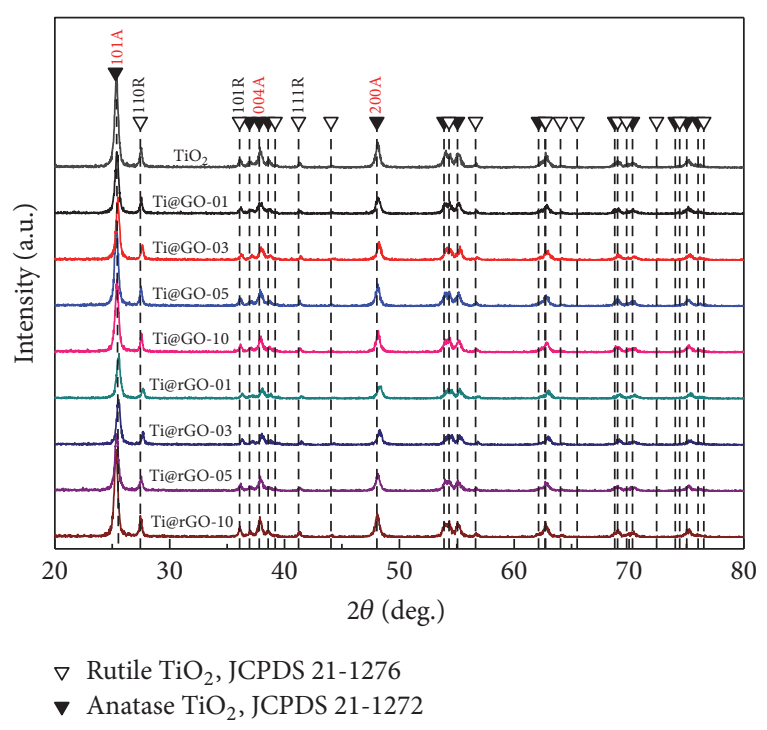

FIgURE 5: XRD patterns of $\mathrm{TiO}_{2}$ and the various graphene/ $/ \mathrm{TiO}_{2}$ composites.

$300 \mathrm{~nm}$, and $600 \mathrm{~nm}$, respectively. These ranges were found to be reasonable and in agreement with that which was reported in related references $[20,21]$.

Figure 8 shows typical UV-Vis spectra of the various solid graphene/ $\mathrm{TiO}_{2}$ composites. As a result, the bandgap energy values of various samples were determined and are summarized in Table 2. The calculated bandgap energy of the neat $\mathrm{TiO}_{2}$ was $3.03 \mathrm{eV}$, which is similar to that which has been reported in the literature [22]. After applying GO to $\mathrm{TiO}_{2}$, the bandgap energy values of the composites only slightly decreased to the range of $2.97-2.99 \mathrm{eV}$. The values did not change significantly with the concentration of GO, probably due to the fact that the amount of GO used for modifying $\mathrm{TiO}_{2}$ was marginal. Therefore, the interaction between $\mathrm{TiO}_{2}$ and $\mathrm{GO}$ was not different, regardless of the GO concentration. A similar effect was observed when $\mathrm{rGO}$ was applied to $\mathrm{TiO}_{2}$. In this latter case, the bandgap energy values of $\mathrm{rGO} / \mathrm{TiO}_{2}$ ranged between 2.95 and $3.02 \mathrm{eV}$. Figure 9 shows XPS spectra of various graphene and graphene/ $\mathrm{TiO}_{2}$ composite materials. After deconvolution, 5 different peaks can be designated. These are those representing $\mathrm{sp}^{2}$ of $\mathrm{C}=\mathrm{C} / \mathrm{C}-\mathrm{C}$ (of the basal plane) at $284.97 \mathrm{eV}, \mathrm{C}-\mathrm{OH}$ (of the hydroxyl group) at $285.88 \mathrm{eV}, \mathrm{C}-\mathrm{O}-\mathrm{C}$ (of the epoxide group) at $286.86 \mathrm{eV},>\mathrm{C}=\mathrm{O}$ (of the carbonyl group) at $287.84 \mathrm{eV}$, and $\mathrm{C}(\mathrm{O}) \mathrm{OH}$ (of the carboxyl group) at $288.94 \mathrm{eV}$. From the above results, it can be seen that intensity of the peaks representing the carbonyl and the epoxide groups decreased after thermal reduction. Intensity of the peaks representing carbon-carbon bonds in the annealed GO (Figure 9(b)) is also greater than those of the annealed rGO (Figure $9(\mathrm{~d})$ ). This suggests that electrical properties of the former should be better than of the latter. The above results also imply that the thermal reduction method is more effective than the chemical reduction approach, taking into account the relative intensity of the C-C peaks from the two systems. For the composite materials, it is also noteworthy that the intensity of the peaks relating to the carboxylic group of Ti@rGO-01 (Figure 9(e)) increased after annealing. This suggests that $\mathrm{TiO}_{2}$ might induce the oxidation of $\mathrm{rGO}$ phase in the composite during heat treatment.

By using the above bandgap energy values in combination with the energy levels of each electrode system, which was determined from the XPS technique, the energy band diagrams of the DSSCs can be evaluated and are illustrated in Figure 10. The diagram mentioned in Figure 10 reveals that the valence band (VB), the conduction band (CB), and the bandgap energy values of Ti@GO are $2.33,-0.65$, and $2.98 \mathrm{eV}$, respectively. The energy levels of $\mathrm{CB}$ and $\mathrm{VB}$ of the composite electrode also lied between those of the adjacent layers (the FTO and the adsorbed dye), implying the efficient transportation of electrons and holes in the system.

In terms of light harvesting properties, considerations of the UV-visible spectra of various materials in the liquid suspension state (Figure 11) revealed that the neat GO is also capable of absorbing light in a wide wavelength, ranging from $200 \mathrm{~nm}$ to $600 \mathrm{~nm}$. Notably, this absorption range is also overlapping with the light absorption of the dye. The intensity from the absorption peaks of graphene $/ \mathrm{TiO}_{2}$ composites is also greater than that of the neat $\mathrm{TiO}_{2}$. The absorption intensity of $\mathrm{TiO}_{2}$ initially increased with the concentration of $\mathrm{GO}$, to the maximum value at $0.10 \mathrm{wt} \% \mathrm{GO}$ loading. At a higher concentration of GO $(0.15 \mathrm{wt} \%)$, however, the intensity dropped again. This was probably due to some agglomeration of the graphene oxide. Similarly, rGO was capable of absorbing light in a wavelength ranging from 210 to $350 \mathrm{~nm}$. The absorbance of $\mathrm{rGO} / \mathrm{TiO}_{2}$ composites was also greater than that of the neat $\mathrm{TiO}_{2}$. The absorbance of $\mathrm{rGO} / \mathrm{TiO}_{2}$ composites seems to be slightly inferior to those of the $\mathrm{GO} / \mathrm{TiO}_{2}$ system. Nevertheless, the above results imply that the absorbance of the dye, which is the actual light harvester for the DSSC system, could be interfered with or suppressed by the graphene/ $\mathrm{TiO}_{2}$ electrode. The above phenomenon might affect the power conversion efficiency of the cells.

3.3. Photovoltaic Performance of the $\mathrm{GO} / \mathrm{TiO}_{2}$ Based DSSCs. Figure 12 shows typical $I-V$ curves of the various DSSCs, resulting in photovoltaic parameters that are determined and summarized in Table 3. It can be seen that the $V_{\text {oc }}$ values of the cells hardly changed with the concentration of GO used for modifying the $\mathrm{TiO}_{2}$ photoelectrode. This suggests that the addition of graphene did not affect the Fermi level of $\mathrm{TiO}_{2}[1,13,14]$. However, the short-circuit current density $\left(J_{\mathrm{sc}}\right)$ and the power conversion efficiency (PCE) values of the $\mathrm{GO} / \mathrm{TiO}_{2}$ based cells are greater than those of the normal cell (without graphene). The PCE value of the cell initially increased when $0.01 \mathrm{wt} \%$ of GO was applied to the $\mathrm{TiO}_{2}$ electrode. After that, the PCE value of the cells decreased again with the increase of the concentration of GO in the composite electrode. In our opinion, it seems that the effects of GO on the photovoltaic performance of the DSSC based on the $\mathrm{TiO}_{2}$ electrode were not straightforward, depending on the concentration of the graphene oxide. In fact, a similar trend was noted by Kusumawati et al. [14] and Wang et al. [13] whereby the relationship between the concentration of graphene and PCE and $J_{\mathrm{sc}}$ of the cell was nonlinear and 


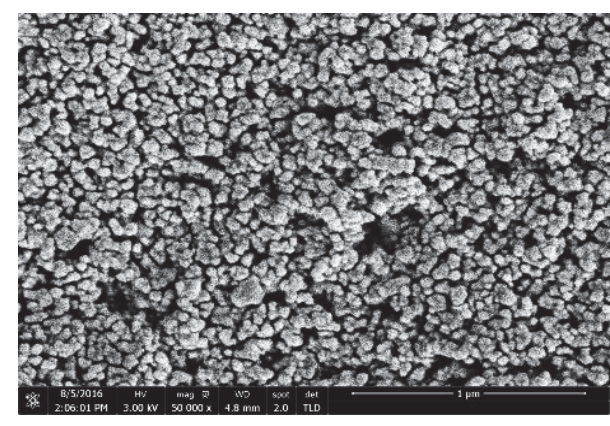

(a) Ti@GO-10

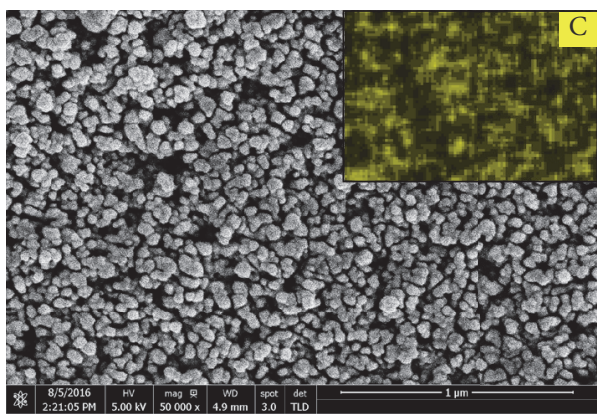

(c) Ti@GO-10 (after heat treatment)

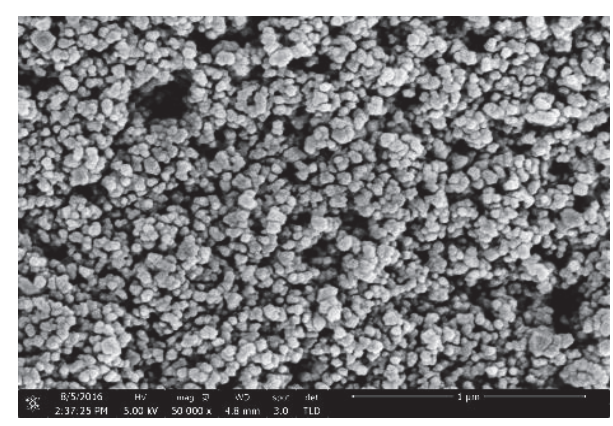

(b) Ti@rGO-10

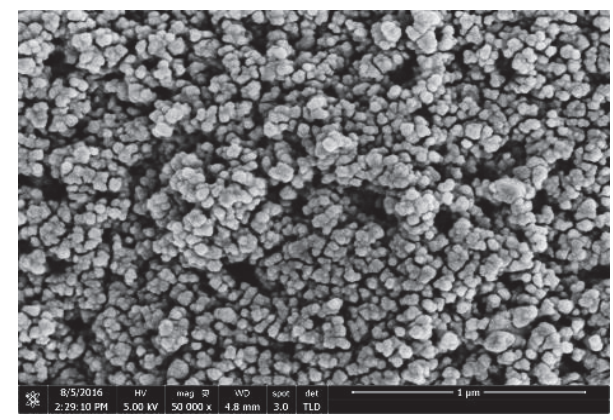

(d) Ti@rGO-10 (after heat treatment)

Figure 6: SEM images of $\mathrm{GO} / \mathrm{TiO}_{2}$ and $\mathrm{rGO} / \mathrm{TiO}_{2}$ composites, before and after heat treatment (inset images are EDS mapping of carbon element).

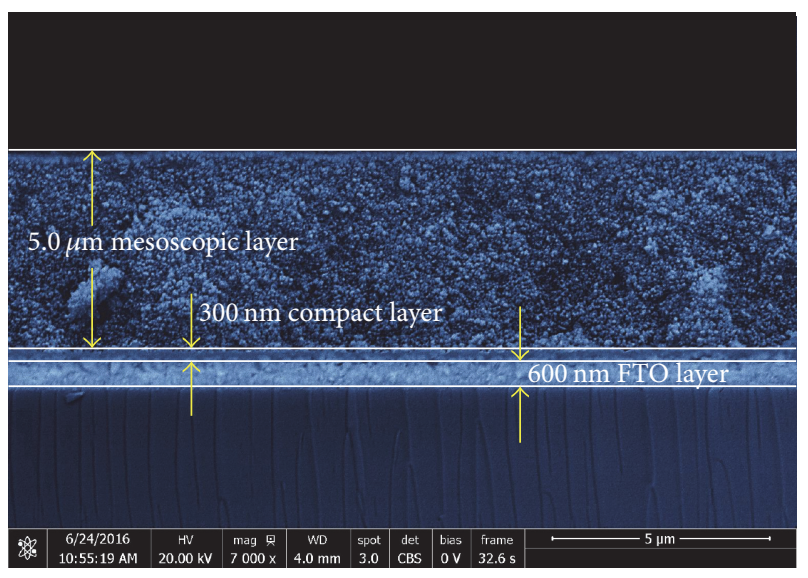

FIGURE 7: SEM image of the cross section of the DSSC photoanode comprised of FTO, compact layer, and the $\mathrm{TiO}_{2}$ based mesoscopic layer(Ti@GO-01).

exhibited a kind of volcano shape. In this regard, it was believed that the presence of GO in the DSSC system not only affected the performance of the $\mathrm{TiO}_{2}$ electrode, but also influenced the performance of other components in the cell. It was also possible that these effects were competing. Generally, the promoting effects of reduced graphene oxides on the DSSC performance of $\mathrm{TiO}_{2}$ have been attributed to several mechanisms. These include (i) the increase of dye loading due to the higher surface area of the graphene modified photoelectrode and (ii) the decrease of electronhole recombination due to the enhancement of electron

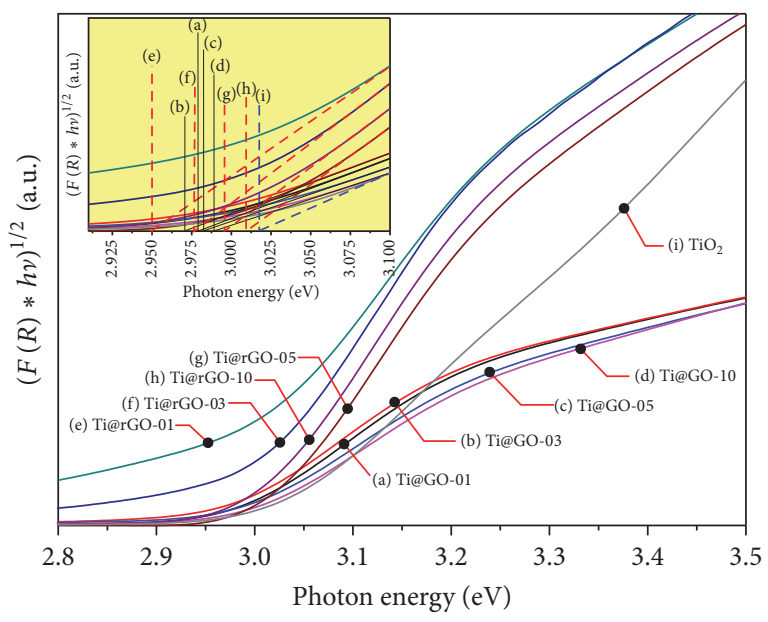

Figure 8: UV-Vis spectra of the various solid graphene/ $\mathrm{TiO}_{2}$ composites.

transfer from $\mathrm{TiO}_{2}$ to the photoelectrode. For example, work by Wang et al. [13] showed that the percentage of the dye loading of graphene $/ \mathrm{TiO}_{2}$ electrodes did not change with the GO content, and the promoting effect of GO on the DSSC performance of $\mathrm{TiO}_{2}$ was attributed to the greater electron transfer. On the other hand, Kusumawati et al. [14] reported that, by using $\mathrm{GO} / \mathrm{TiO}_{2}$ as a replacement of $\mathrm{TiO}_{2}$, the charge transfer of the system did not change, regardless of the GO content. In that case, the better performance of the DSSC based on the $\mathrm{GO} / \mathrm{TiO}_{2}$ electrode resulted in a higher amount of dye loading in the cell. 


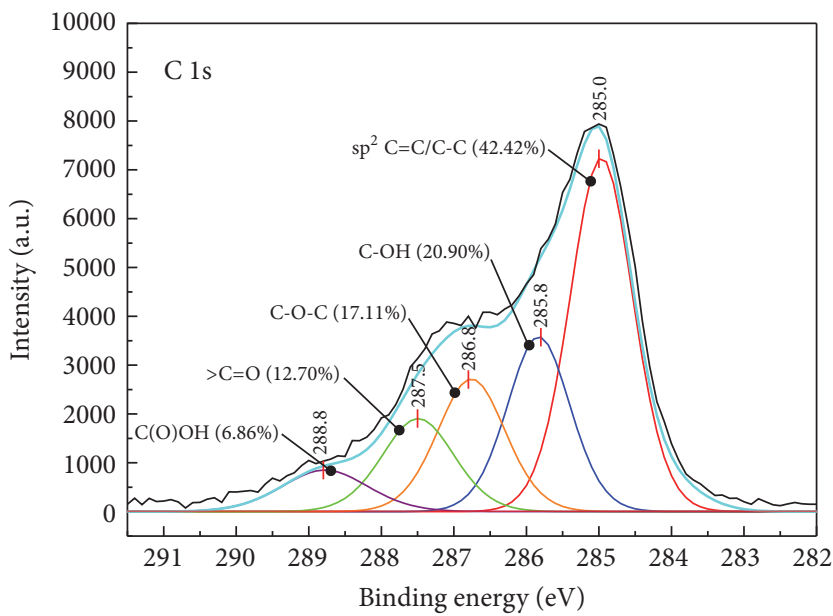

(a)

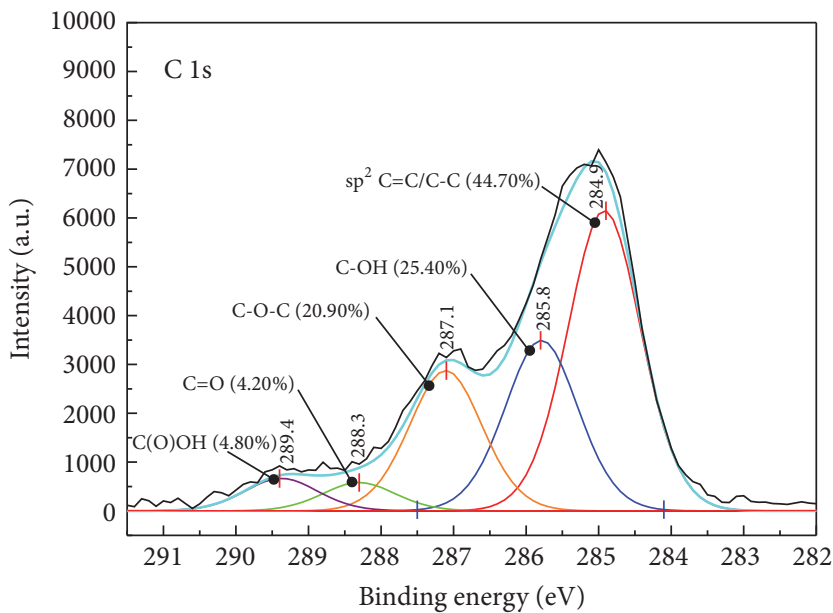

(c)

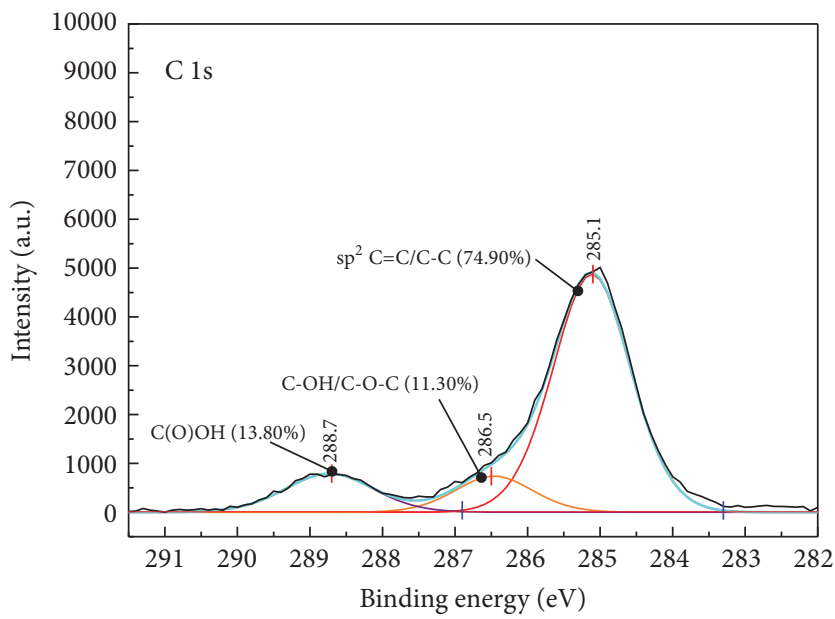

(e)

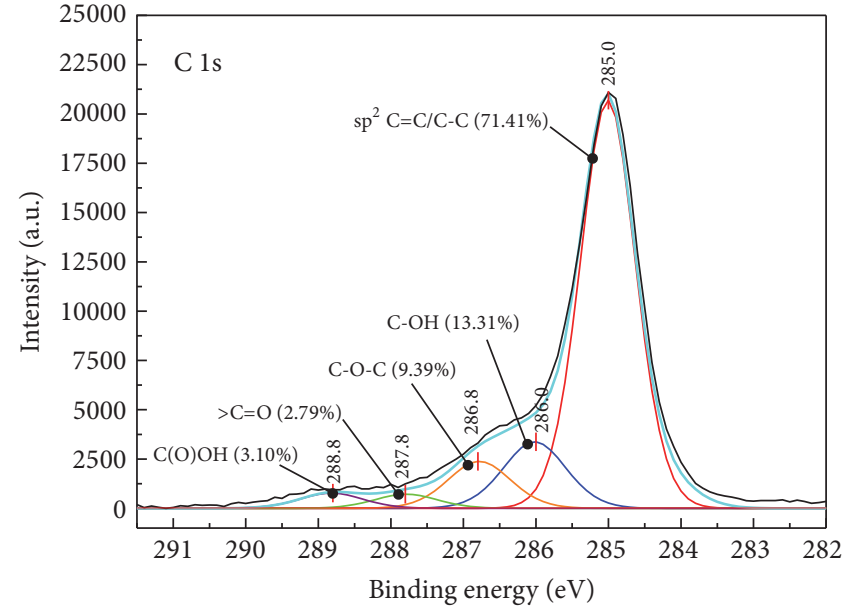

(b)

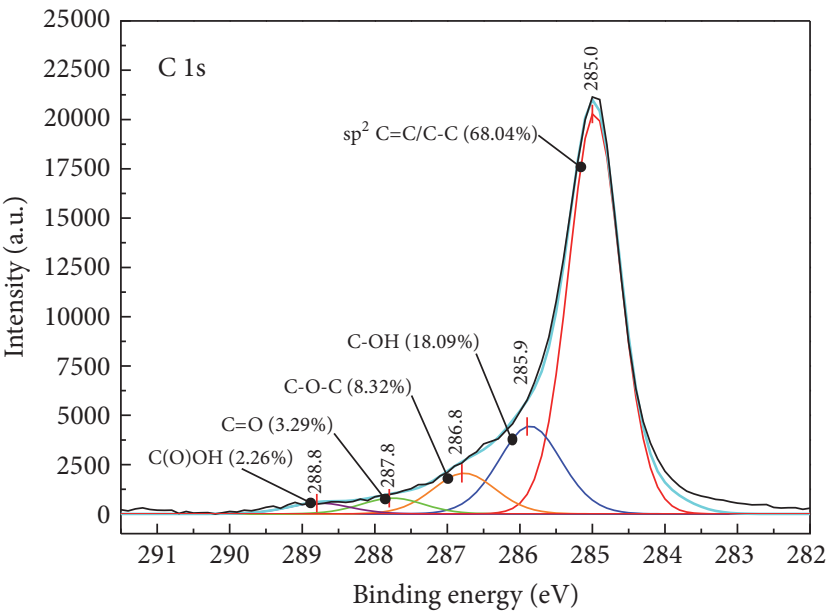

(d)

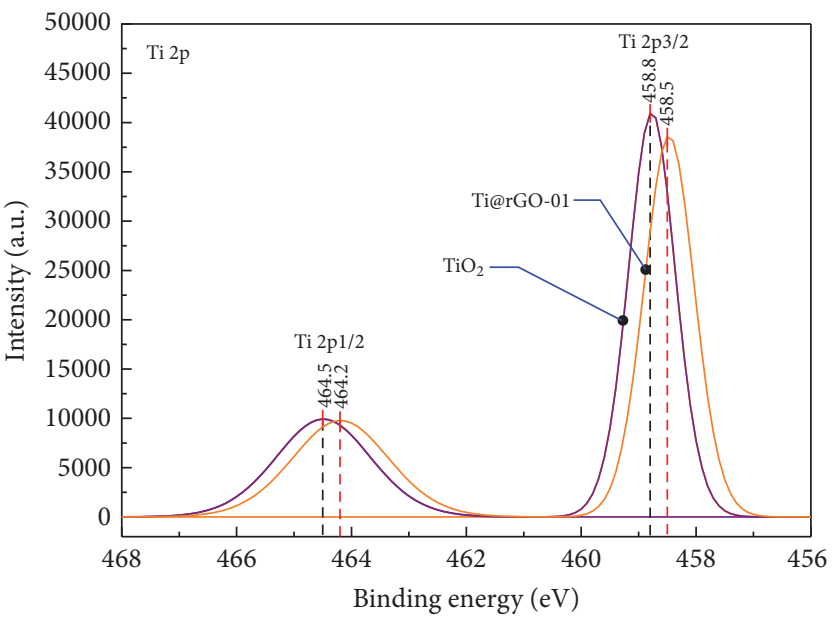

(f)

FIGURE 9: XPS spectra of various graphene based materials: (a) C 1s of GO (before heat treatment); (b) C 1s of GO (after heat treatment); (c) $\mathrm{C}$ 1s of rGO (before heat treatment); (d) C 1s of rGO (after heat treatment); (e) C 1s of Ti@rGO-01; (f) Ti 2p of Ti@rGO-01. 
TABLE 3: Short-circuit current density $\left(J_{\text {sc }}\right)$, open-circuit voltage $\left(V_{\mathrm{oc}}\right)$, fill factor (FF), power conversion efficiency (PCE), charge recombination resistance $\left(R_{\text {rec }}\right)$, and electron lifetime $\left(\tau_{e}\right)$ of the DSSCs containing various types and amounts of graphene.

\begin{tabular}{|c|c|c|c|c|c|c|}
\hline Sample codes & $J_{\mathrm{sc}}\left(\mathrm{mA} / \mathrm{cm}^{2}\right)$ & $V_{\text {oc }}(\mathrm{V})$ & $\mathrm{FF}$ & PCE (\%) & $R_{2 \text { rec }}(\Omega)$ & $\tau_{e}(\mu \mathrm{sec})$ \\
\hline $\mathrm{TiO}_{2}$ & 6.27 & 0.71 & 60.28 & 2.68 & 14.07 & 79.74 \\
\hline Ti@GO-01 & 8.42 & 0.68 & 63.99 & 3.69 & 26.74 & 226.81 \\
\hline Ti@GO-03 & 7.51 & 0.68 & 62.98 & 3.22 & 20.94 & 150.22 \\
\hline Ti@GO-05 & 7.14 & 0.69 & 64.7 & 3.2 & 19.18 & 119.46 \\
\hline Ti@GO-10 & 6.22 & 0.7 & 66.83 & 2.92 & 16.09 & 105.21 \\
\hline Ti@rGO-01 & 2.79 & 0.63 & 72.23 & 1.28 & 5.79 & 26.51 \\
\hline Ti@rGO-03 & 6.31 & 0.7 & 65.29 & 2.9 & 16.08 & 92.83 \\
\hline Ti@rGO-05 & 5.52 & 0.63 & 64.11 & 2.38 & 10.51 & 54.99 \\
\hline Ti@rGO-10 & 5.38 & 0.63 & 65.56 & 2.32 & 9.08 & 42.81 \\
\hline
\end{tabular}

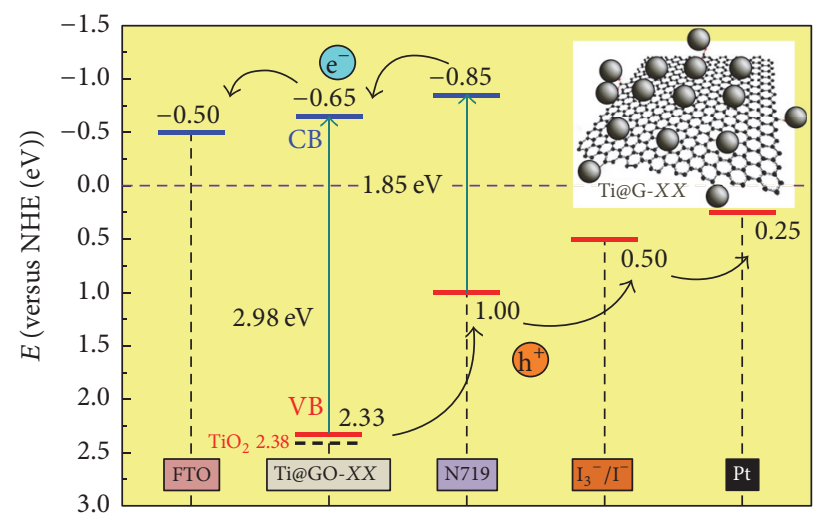

FIGURE 10: Band diagram of DSSC containing graphene/ $/ \mathrm{TiO}_{2}$ electrode.

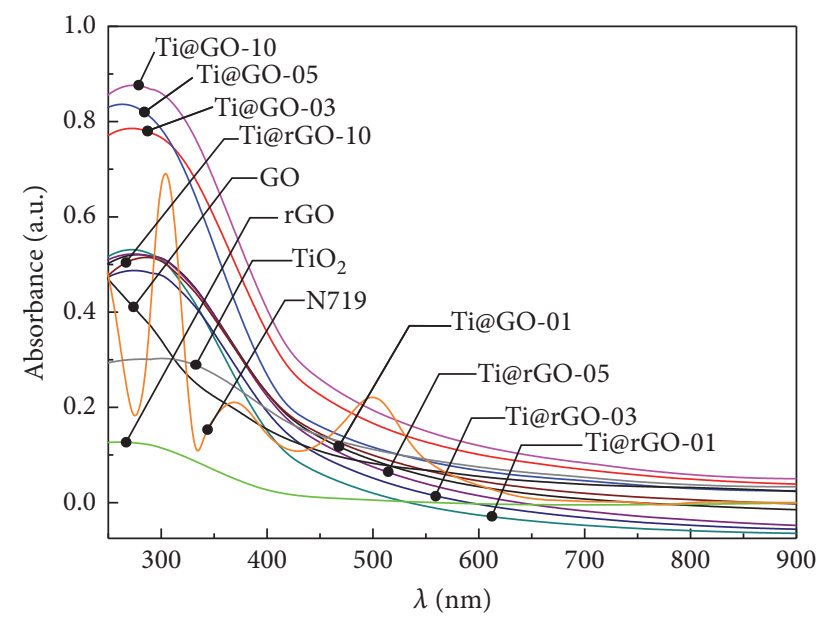

Figure 11: UV-Vis spectra of $\mathrm{TiO}_{2}, \mathrm{GO}, \mathrm{rGO}$, and the various graphene $/ \mathrm{TiO}_{2}$ electrodes.

In this study, we found that the percentage of dye loading of the $\mathrm{TiO}_{2}$ based electrodes did not increase after applying GO into the $\mathrm{TiO}_{2}$ electrode (Figure 13). Therefore, the greater PCE of the cells containing graphene could be attributed to some other factors. Figures 14 and 15 show EIS spectra and Bode imaginary plots of various DSSCs. In addition, the equivalent circuit, representing the cell reaction under the backward condition, was also illustrated. Generally, the term $R_{1}$ refers to ohmic series resistance, describing the contact between $\mathrm{FTO} / \mathrm{TiO}_{2}$ interfaces. The parameter $Z_{W 2}$ denotes charge diffusion impedance of the electron in $\mathrm{TiO}_{2}$ electrode whereas $R_{2}$ refers to charge recombination resistance $\left(R_{\mathrm{rct}}\right)$ of the $\mathrm{TiO}_{2}$ based electrode. In this study, it was found that $R_{1}$ did not change with the type and concentration of the graphene used. However, $R_{\mathrm{rct}}$ value of the cells increased after applying $\mathrm{GO}$ into the $\mathrm{TiO}_{2}$ electrode. Lifetime of the electron $\left(\tau_{e}\right)$ in the $\mathrm{GO} / \mathrm{TiO}_{2}$ based DSSCs was also longer than that of the normal DSSC based on the neat $\mathrm{TiO}_{2}$ electrode. The above results suggest that the electron-hole recombination in the system could be suppressed and that contributed to the greater efficiency of the DSSCs. In addition, a consideration of the energy band diagrams (Figure 10) of the graphene/ $\mathrm{TiO}_{2}$ based DSSCs suggested that transportation of electron and hole from the excited dye toward the corresponding electrode could be facilitated with the presence of the graphene/ $/ \mathrm{TiO}_{2}$ electrode. The above effect could be related to the better PCE of the cell.

It is noteworthy, as mentioned above, that the relationship between GO content and the PCE values of the cells was nonlinear. The efficiency values decreased as the concentration of GO was further increased above $0.01 \mathrm{wt} \%$. In our opinion, this could be related to other effects, including the lower light harvesting property of the dye, which was suppressed by the absorption of light by GO in a similar wavelength range (200-800 nm) (Figure 11). Consequently, the number of photogenerated electrons was reduced and that contributed to the decrease in PCE values of the DSSCs at the high concentration of GO. This effect is similar to that which was observed by Wang et al. [13].

3.4. Photovoltaic Performance of the $\mathrm{rGO} / \mathrm{TiO}_{2}$ Based DSSCs. When rGO was used as a replacement of GO in the composites electrode, a similar trend was observed, except that the optimum concentration of rGO yielding the highest PCE value of DSSC had shifted to $0.03 \mathrm{wt} \%$. Beyond this concentration, the PCE values of the system decreased again. The relationship between rGO content and various parameters, such as $J_{\mathrm{sc}}, R_{\text {rec }}$, and $\tau_{e}$, also followed that same trend. By applying more than $0.03 \mathrm{wt} \%$ of rGO, the $V_{\mathrm{oc}}$ value significantly dropped. This indicates that the Fermi level of the $\mathrm{TiO}_{2}$ electrode was affected by the presence of rGO. In this case, 


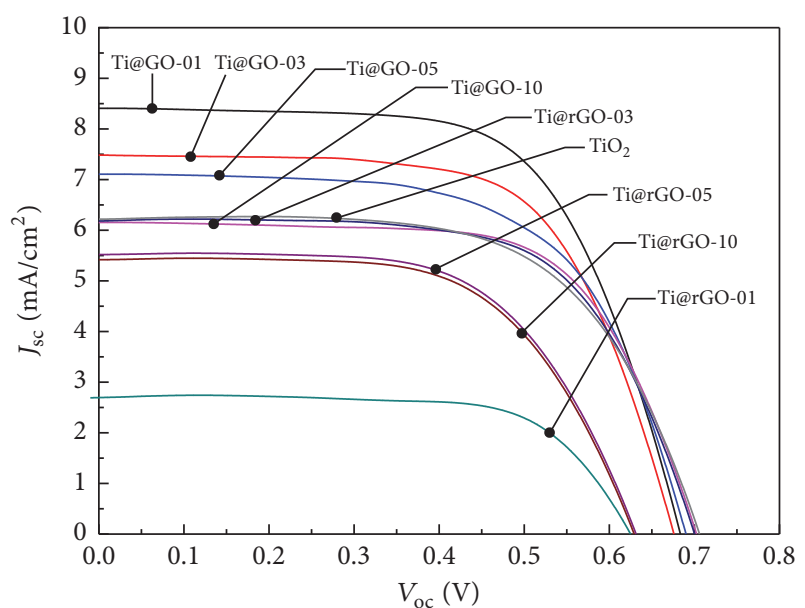

Figure 12: $J-V$ curves of DSSCs containing different types of $\mathrm{TiO}_{2}$ based electrodes.

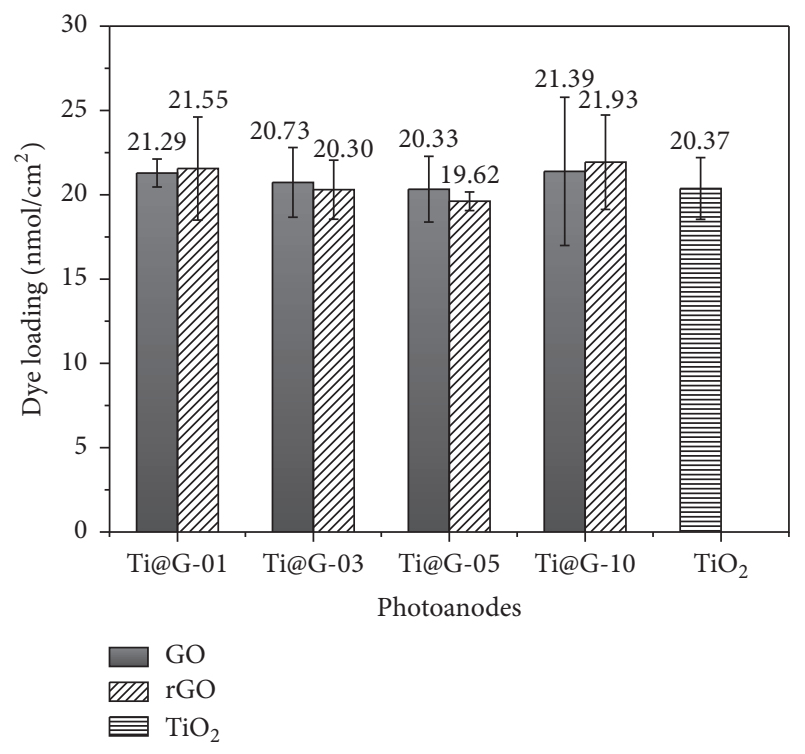

FIGURE 13: Dye loading contents of various $\mathrm{TiO}_{2}$ based electrodes.

this was probably because some electron-hole recombination at the interface between graphene and liquid electrolyte occurred and contributed to the lower $V_{\text {oc }}$ values and the shift of the Fermi level of the $\mathrm{rGO} / \mathrm{TiO}_{2}$ composite electrode.

It is also worth noting that the PCE values of many DSSCs based on $\mathrm{rGO} / \mathrm{TiO}_{2}$ electrodes were lower than those of the $\mathrm{GO} / \mathrm{TiO}_{2}$ based DSSCs, provided that the same concentration of graphene was used (0.01-0.05 wt\%). In our opinion, the above discrepancy can be related to several factors, including the differences in light absorption properties and charge transportation of the two electrode systems. For example, the above results from EIS technique (Figures 14 and 15) show that charge recombination resistance and electron lifetime of the $\mathrm{GO} / \mathrm{TiO}_{2}$ based DSSCS are greater than those of the $\mathrm{rGO} / \mathrm{TiO}_{2}$ based cells. Raman spectra of the composite electrodes (Figure 16) also showed that the characteristic D and $\mathrm{G}$ bands of the reduced graphene oxide in the composite (Ti@rGO-05) disappeared after the heat treatment process.

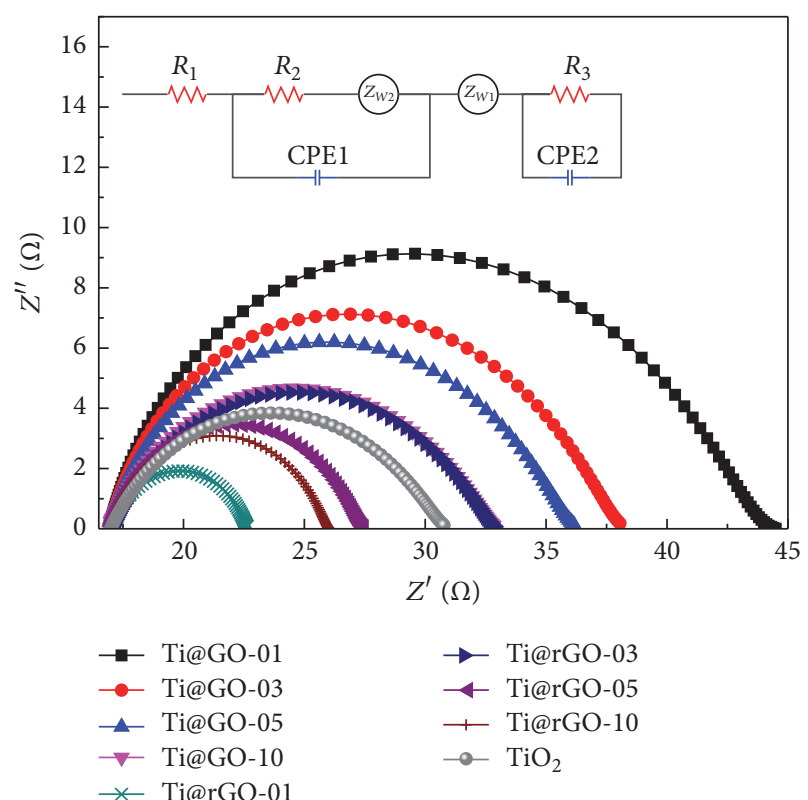

FIgURE 14: EIS spectra of various $\mathrm{TiO}_{2}$ and graphene/ $/ \mathrm{TiO}_{2}$ based DSSCs.

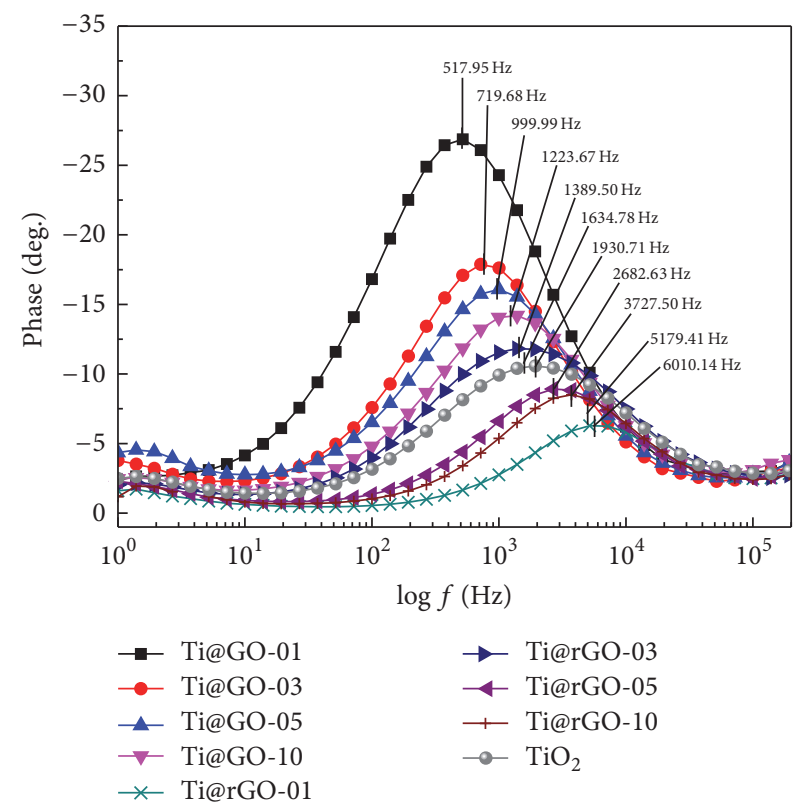

FIGURE 15: Bode imaginary plots for the impedance of DSSCs containing different types of $\mathrm{TiO}_{2}$ based photoanodes.

This was not the case of the $\mathrm{GO} / \mathrm{TiO}_{2}$ composite (Ti@GO05). It is apparent that the rGO phase in the $\mathrm{TiO}_{2} / \mathrm{rGO}$ composite was partially degraded during the heat treatment process. In our opinion, it was believed that the presence of $\mathrm{TiO}_{2}$ in the composite had induced the degradation of the rGO via some possible mechanisms such as scission and oxidation of the graphene plane. This resulted in the formation of oxidized functional groups such as carboxylic acid on the edge [23]. The above notion was supported by the result from XPS technique in which the $\mathrm{C}$ 1s peak at $288.74 \mathrm{eV}$ emerged (Figure 9(e)). 
TABLE 4: Comparative DSSC performance of the various graphene/ $/ \mathrm{TiO}_{2}$ electrodes from different works.

\begin{tabular}{|c|c|c|c|c|c|}
\hline \multirow[b]{2}{*}{ References } & \multicolumn{3}{|c|}{ Cell descriptions } & \multicolumn{2}{|c|}{ PCE (\%) of cells with different electrodes } \\
\hline & Photoanode materials & $\begin{array}{l}\text { Optimum graphene } \\
\text { content (wt\%) }\end{array}$ & Active area $\left(\mathrm{cm}^{2}\right)$ & Graphene $/ \mathrm{TiO}_{2}$ & Bare $\mathrm{TiO}_{2}$ \\
\hline Wang et al., 2012 & $\mathrm{GO} / \mathrm{TiO}_{2}$ & 0.83 & 0.50 & 2.78 & 1.79 \\
\hline Kusumawati et al., 2014 & $\mathrm{GO} / \mathrm{TiO}_{2}$ & 1.20 & 0.36 & 7.49 & 5.78 \\
\hline Cheng and Stadler, 2015 & $\mathrm{GO} / \mathrm{TiO}_{2}$ & 1.60 & 0.25 & 7.68 & 4.78 \\
\hline Chou et al., 2015 & $\mathrm{GO} / \mathrm{TiO}_{2}$ & 0.05 & 0.57 & 5.26 & $\mathrm{n} / \mathrm{a}$ \\
\hline Ding et al., 2015 & $\mathrm{rGO} / \mathrm{TiO} 2$ & 0.75 & $\mathrm{n} / \mathrm{a}$ & 7.89 & 6.06 \\
\hline Tang et al., 2010 & $\mathrm{rGO} / \mathrm{TiO}_{2}$ & $10.0^{*}$ & 0.25 & 1.68 & 0.32 \\
\hline This study & $\mathrm{rGO} / \mathrm{TiO}_{2}$ & 0.03 & 0.40 & 2.90 & 2.68 \\
\hline This study & $\mathrm{rGO} / \mathrm{TiO}_{2}$ & 0.01 & 0.40 & 1.28 & 2.68 \\
\hline This study & $\mathrm{GO} / \mathrm{TiO}_{2}$ & 0.01 & 0.40 & 3.69 & 2.68 \\
\hline
\end{tabular}

* refers to \%w/v of RGO as compared to titanium(IV) butoxide colloids.

Last but not least, for comparative purposes, the best PCE values of DSSCs based on graphene/ $\mathrm{TiO}_{2}$ electrodes from this study and those reported in some additional literature are summarized in Table 4. It is noteworthy that the PCE values of DSSCs obtained from this study are in a reasonable range, even though some discrepancies can be seen. In our opinion, these differences can be attributed to several factors including the graphene content, the actual thickness of each layer in the devices, and the active area of the cells. Nevertheless, overall, our results demonstrate that a small amount of graphene oxide (0.01-0.05 wt\%), which was thermally reduced in situ during the fabrication process of DSSC, can be used to promote the photovoltaic performance of the $\mathrm{TiO}_{2}$ electrode. In this regard, the photovoltaic performance of the graphene/ $\mathrm{TiO}_{2}$ electrodes in the perovskite solar cell also deserves consideration and in fact is an aspect included in our ongoing work.

\section{Conclusions}

(1) Two different types of graphene based materials were successfully prepared by using two different approaches:

(i) The reduced graphene oxide which was pretreated with a mild reducing agent (vitamin C) prior to use (the so-called rGO herein).

(ii) The graphene oxide which could be thermally reduced in situ (the so-called GO) during the annealing step of the solar cell fabrication process.

(2) The prepared graphene was capable of harvesting light in the wavelength which overlapped with that of the dye. The light absorption intensity of the $\mathrm{TiO}_{2}$ based composites also increased with the graphene concentration. These factors contributed to the lowering of the power conversion efficiency of the $\mathrm{TiO}_{2}$ based DSSCs.

(3) The relationships between the concentration of (r)GO in the graphene/ $\mathrm{TiO}_{2}$ based photoanodes and the power conversion efficiency (PCE) of the DSSCs

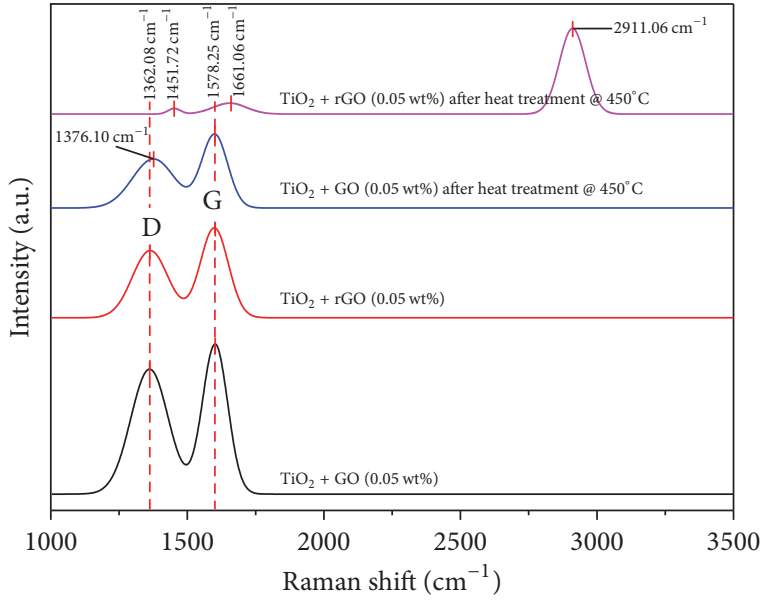

FIGURE 16: Raman spectra of graphene/ $\mathrm{TiO}_{2}$ composites both before and after heat treatment.

were nonlinear. The PCE initially increased in the presence of $0.01 \mathrm{wt} \%$ of GO. As the GO was further increased, the PCE value decreased. Similar effects were observed when rGO was used as a dopant.

(4) Regardless of the graphene types, the promoting effect of graphene on the photovoltaic performance of $\mathrm{TiO}_{2}$ was related to the greater resistance to electron-hole recombination and a longer electron lifetime. On the other hand, the decreasing trends of PCE and $J_{\text {sc }}$ values of DSSCs of high graphene (GO and/or rGO) content can be ascribed to the competing light harvesting efficiency between the dye and the graphene.

(5) In this study, the maximum power conversion efficiency value of DSSC $\left(3.69 \%, \mathrm{FF}=63.98, V_{\mathrm{oc}}=\right.$ 0.68 , and $\left.I_{\mathrm{sc}}=8.42\right)$ was obtained when only a small amount $(0.01 \mathrm{wt} \%)$ of the thermally reduced GO was added to the $\mathrm{TiO}_{2}$ based photoelectrode. This corresponded to an improvement of $73 \%$, compared to that of the DSSC employing the bare $\mathrm{TiO}_{2}$ electrode $\left(2.13 \%, \mathrm{FF}=65.07, V_{\mathrm{oc}}=0.68\right.$, and $\left.I_{\mathrm{sc}}=4.75\right)$. 


\section{Conflicts of Interest}

The authors declare that there are no conflicts of interest regarding the publication of this paper.

\section{Acknowledgments}

This work has been supported by the Nanotechnology Center (Nanotec), NSTDA, Ministry of Science and Technology, Thailand, through its programme of the Center of Excellence Network.

\section{References}

[1] http://www.nrel.gov/ncpv/images/efficiency_chart.jpg.

[2] H. Ding, S. Zhang, J.-T. Chen et al., "Reduction of graphene oxide at room temperature with vitamin $\mathrm{C}$ for $\mathrm{RGO}-\mathrm{TiO}_{2}$ photoanodes in dye-sensitized solar cell," Thin Solid Films, vol. 584, pp. 29-36, 2015.

[3] Y.-B. Tang, C.-S. Lee, J. Xu et al., "Incorporation of graphenes in nanostructured $\mathrm{TiO}_{2}$ films via molecular grafting for dyesensitized solar cell application," ACS Nano, vol. 4, no. 6, pp. 3482-3488, 2010.

[4] G. S. Han, Y. H. Song, Y. U. Jin et al., "Reduced graphene oxide/mesoporous $\mathrm{TiO}_{2}$ nanocomposite based perovskite solar cells," ACS Applied Materials and Interfaces, vol. 7, no. 42, pp. 23521-23526, 2015.

[5] S. Park, J. An, I. Jung et al., "Colloidal suspensions of highly reduced graphene oxide in a wide variety of organic solvents," Nano Letters, vol. 9, no. 4, pp. 1593-1597, 2009.

[6] A. K. Swain and D. Bahadur, "Enhanced stability of reduced graphene oxide colloid using cross-linking polymers," Journal of Physical Chemistry C, vol. 118, no. 18, pp. 9450-9457, 2014.

[7] M. J. Fernández-Merino, L. Guardia, J. I. Paredes et al., "Vitamin $\mathrm{C}$ is an ideal substitute for hydrazine in the reduction of graphene oxide suspensions," Journal of Physical Chemistry C, vol. 114, no. 14, pp. 6426-6432, 2010.

[8] J. Zhang, H. Yang, G. Shen, P. Cheng, J. Zhang, and S. Guo, "Reduction of graphene oxide via L-ascorbic acid," Chemical Communications, vol. 46, no. 7, pp. 1112-1114, 2010.

[9] Y. Matsumoto, M. Koinuma, S. Y. Kim et al., "Simple photoreduction of graphene oxide nanosheet under mild conditions," ACS Applied Materials and Interfaces, vol. 2, no. 12, pp. 34613466, 2010.

[10] A. Hasani, H. Sharifi Dehsari, A. Amiri Zarandi, A. Salehi, F. A. Taromi, and H. Kazeroni, "Visible light-assisted photoreduction of graphene oxide using CdS nanoparticles and gas sensing properties," Journal of Nanomaterials, vol. 2015, Article ID 930306, 11 pages, 2015.

[11] H. Tong, J. Zhu, J. Chen et al., "Electrochemical reduction of graphene oxide and its electrochemical capacitive performance," Journal of Solid State Electrochemistry, vol. 17, no. 11, pp. 2857-2863, 2013.

[12] W. Chen and L. Yan, "Preparation of graphene by a lowtemperature thermal reduction at atmosphere pressure," Nanoscale, vol. 2, no. 4, pp. 559-563, 2010.

[13] H. Wang, S. L. Leonard, and Y. H. Hu, "Promoting effect of graphene on dye-sensitized solar cells," Industrial and Engineering Chemistry Research, vol. 51, no. 32, pp. 10613-10620, 2012.

[14] Y. Kusumawati, M. A. Martoprawiro, and T. Pauporté, "Effects of graphene in graphene/ $\mathrm{TiO}_{2}$ composite films applied to solar cell photoelectrode," Journal of Physical Chemistry C, vol. 118, no. 19, pp. 9974-9981, 2014.

[15] G. Cheng and F. J. Stadler, "Achieving phase transformation and structure control of crystalline anatase $\mathrm{TiO}_{2} @ \mathrm{C}$ hybrids from titanium glycolate precursor and glucose molecules," Journal of Colloid and Interface Science, vol. 438, pp. 169-178, 2015.

[16] J.-C. Chou, C.-H. Huang, Y.-H. Liao, S.-W. Chuang, L.-H. Tai, and Y.-H. Nien, "Effect of different graphene oxide contents on dye-sensitized solar cells," IEEE Journal of Photovoltaics, vol. 5, no. 4, pp. 1106-1112, 2015.

[17] W. Shu, Y. Liu, Z. Peng, K. Chen, C. Zhang, and W. Chen, "Synthesis and photovoltaic performance of reduced graphene oxide- $\mathrm{TiO}_{2}$ nanoparticles composites by solvothermal method," Journal of Alloys and Compounds, vol. 563, pp. 229-233, 2013.

[18] O. O. Kapitanova, G. N. Panin, A. N. Baranov, and T. W. Kang, "Synthesis and properties of graphene oxide/graphene nanostructures," Journal of the Korean Physical Society, vol. 60, no. 10, pp. 1789-1793, 2012.

[19] W. S. Hummers Jr. and R. E. Offeman, "Preparation of graphitic oxide," Journal of the American Chemical Society, vol. 80, no. 6, p. $1339,1958$.

[20] L. Meng and C. Li, "Blocking layer effect on dye-sensitized solar cells assembled with $\mathrm{TiO}_{2}$ nanorods prepared by dc reactive magnetron sputtering," Nanoscience and Nanotechnology Letters, vol. 3, no. 2, pp. 181-185, 2011.

[21] Y. Zheng, S. Klankowski, Y. Yang, and J. Li, "Preparation and characterization of $\mathrm{TiO}_{2}$ barrier layers for dye-sensitized solar cells," ACS Applied Materials and Interfaces, vol. 6, no. 13, pp. 10679-10686, 2014.

[22] S. Valencia, J. M. Marín, and G. Restrepo, "Study of the bandgap of synthesized titanium dioxide nanoparticules using the sol-gel method and a hydrothermal treatment," Open Materials Science Journal, vol. 4, pp. 9-14, 2009.

[23] M. Xing, W. Fang, X. Yang, B. Tian, and J. Zhang, "Highlydispersed boron-doped graphene nanoribbons with enhanced conductibility and photocatalysis," Chemical Communications, vol. 50, no. 50, pp. 6637-6640, 2014. 

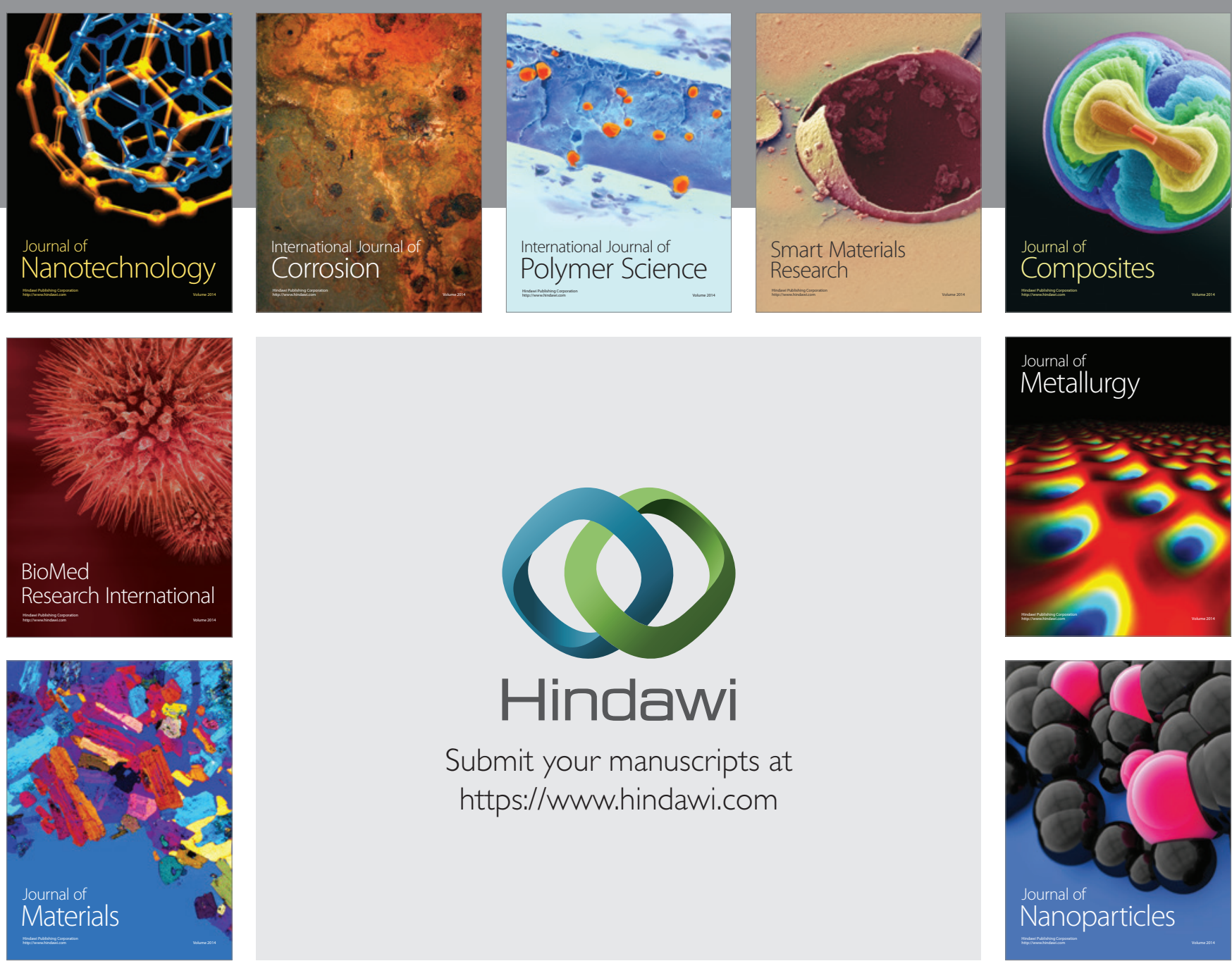

\section{Hindawi}

Submit your manuscripts at

https://www.hindawi.com

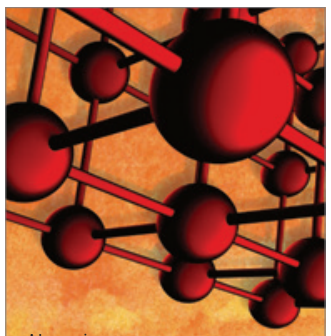

Materials Science and Engineering
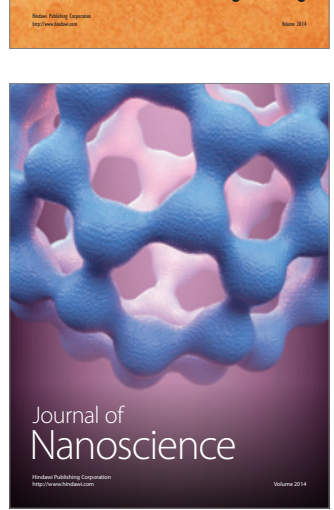
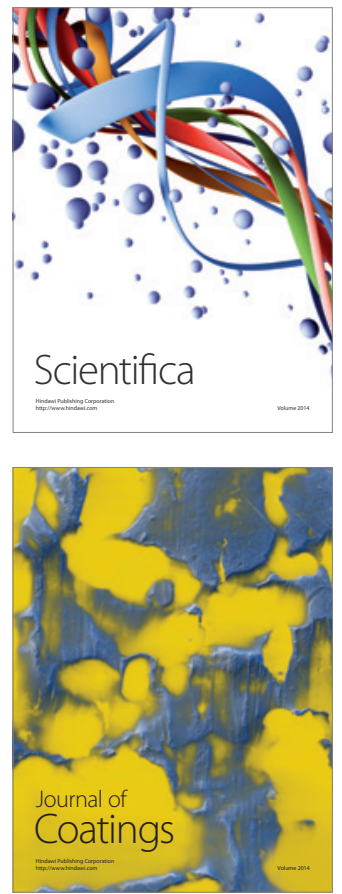
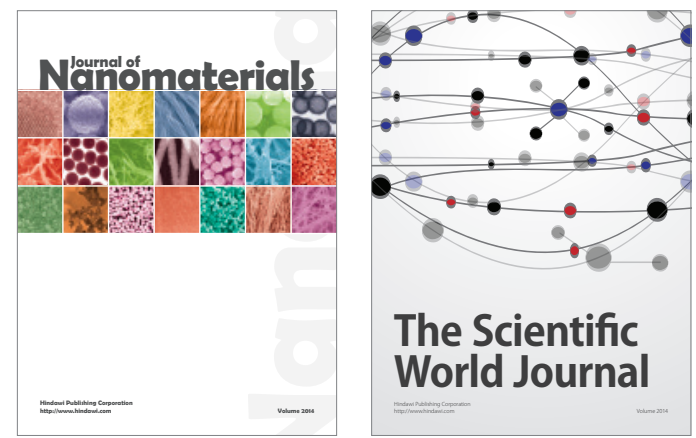

The Scientific World Journal
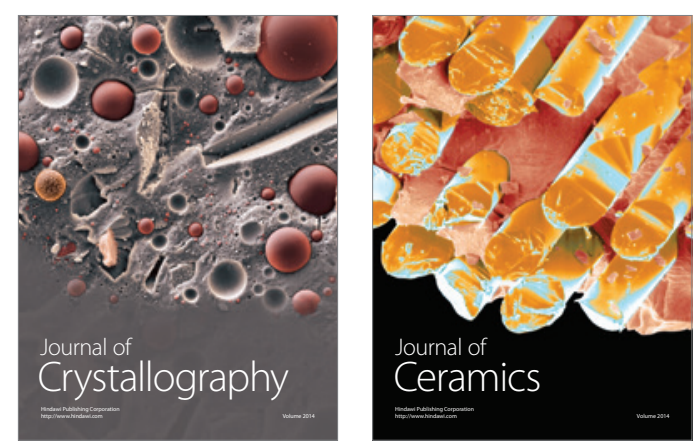
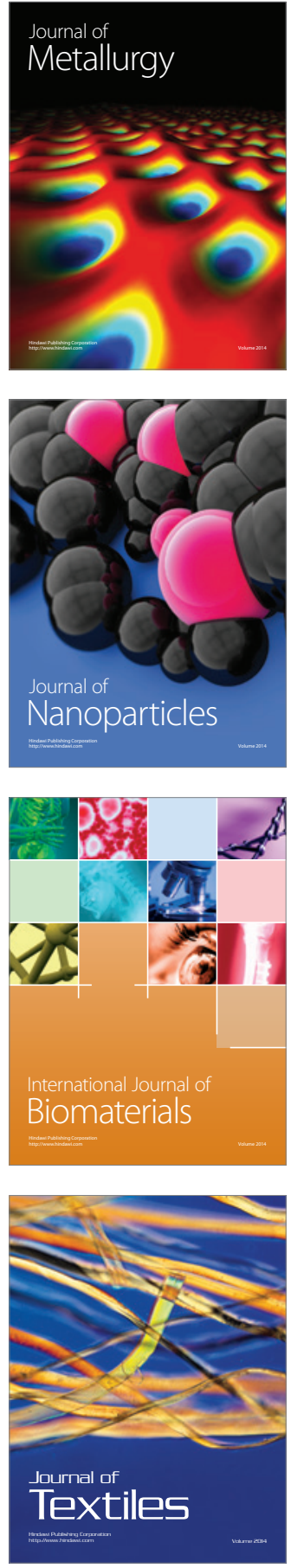